\title{
Fluxos de Capitais e Crescimento Econômico nos Países em Desenvolvimento
}

\author{
Aderbal Oliveira Damasceno \\ Professor - Universidade Federal de Uberlândia (UFU/MG) - Campus Santa Mônica \\ Endereço para contato: Av. João Naves de Ávila, 2121 - Bloco $1 \mathrm{~J}$ - sala 249 \\ Uberlândia - Minas Gerais - Brasil - CEP: 38408-144 - E-mail: damasceno@ie.ufu.br
}

Recebido em 14 de agosto de 2012. Aceito em 08 de agosto de 2013.

\begin{abstract}
Resumo
Este trabalho desenvolve uma análise empírica sobre as relações entre fluxos de capitais e crescimento econômico nos países em desenvolvimento. Os resultados sugerem: i) há evidências de que a poupança externa desestimula o crescimento econômico; ii) não há evidências de que os fluxos de capitais estimulam o crescimento econômico; iii) não existem evidências de que os efeitos da poupança externa e dos fluxos de capitais sobre o crescimento econômico dependem dos níveis de desenvolvimento institucional, desenvolvimento financeiro, abertura comercial, estabilidade macroeconômica e capital humano. Uma possível explicação para esses resultados é a possibilidade dos fluxos de capitais para os países em desenvolvimento levarem a instabilidade macroeconômica, crises financeiras e apreciação cambial, com efeitos adversos sobre o crescimento econômico.
\end{abstract}

\section{Palavras-Chave}

fluxos de capitais, crescimento econômico, países em desenvolvimento

\begin{abstract}
This paper develops an empirical analysis of the relationship between capital flows and economic growth in developing countries. Empirical evidence suggest: i) there is evidence that external savings mitigates economic growth; ii) there is no evidence that capital flows foster economic growth; iii) there is no evidence that external saving and capital flows effects on the economic growth depend on the levels of institutional development, financial development, trade openness, macroeconomic stability and human capital. One possible explanation for these results is the possibility of capital flows to developing countries lead to macroeconomic instability, financial crises and currency appreciation, with adverse effects on economic growth.
\end{abstract}

\section{Keywords}

capital flows, economic growth, developing countries

\section{JEL Classification}

F21, F41, F01

- O autor agradece o auxílio financeiro fornecido pela Fundação de Amparo à Pesquisa do Estado de Minas Gerais (FAPEMIG). 


\section{Introdução}

A literatura teórica apresenta argumentos acerca da existência de benefícios e custos associados aos fluxos de capitais para os países em desenvolvimento. Os potenciais benefícios são suavização da trajetória do consumo e estímulo ao crescimento econômico. Os potenciais custos são crises financeiras e apreciação cambial, o que desestimularia o crescimento econômico. O objetivo deste trabalho é desenvolver uma análise empírica sobre as relações entre fluxos de capitais e crescimento econômico nos países em desenvolvimento. Utilizando dados para 83 países em desenvolvimento durante o período 1980-2004, serão estimadas equações de crescimento especificadas como um modelo dinâmico de dados em painel, incluindo entre as variáveis explanatórias medidas de fluxos de capitais.

O trabalho contribui para a literatura em aspectos importantes: i) ampla amostra de países em desenvolvimento durante um longo período; ii) amplo conjunto de medidas de fluxos de capitais; iii) metodologia econométrica que leva em consideração a possível endogeneidade dos fluxos de capitais; e iv) arcabouço empírico unificado para testar o efeito marginal dos fluxos de capitais sobre o crescimento econômico e se esse efeito marginal depende das características políticas, institucionais e econômicas nos países da amostra. Ademais, a análise empírica sobre as relações entre fluxos de capitais e crescimento econômico nos países em desenvolvimento é particularmente oportuna no contexto atual, dadas as discussões sobre desequilíbrio global e crise financeira global.

Os resultados econométricos sugerem: i) há evidências de que a poupança externa desestimula o crescimento econômico; ii) não há evidências de que os fluxos de capitais estimulam o crescimento econômico; iii) não existem evidências de que os efeitos da poupança externa e dos fluxos de capitais sobre o crescimento econômico dependem dos níveis de desenvolvimento institucional, desenvolvimento financeiro, abertura comercial, estabilidade macroeconômica e capital humano. Uma possível explicação para esses resultados é a possibilidade dos fluxos de capitais para os países em desenvolvimento levarem a instabilidade macroeconômica, crises financeiras e apreciação cambial, com efeitos adversos sobre o crescimento econômico. 
O trabalho está organizado em quatro seções, além desta introdução. $\mathrm{Na}$ seção 2 faz-se uma síntese da literatura teórica e empírica sobre o tema. Na seção 3 apresentam-se os procedimentos metodológicos utilizados. Na seção 4 apresentam-se os resultados dos testes econométricos. Por fim, na seção 5 , alinham-se algumas considerações finais.

\section{Síntese da Literatura Teórica e Empírica}

\subsection{Fluxos de Capitais e o Modelo Neoclássico}

No modelo neoclássico de crescimento (Solow-Swan, Ramsey-CassKoopmans), se todos os países têm acesso à mesma tecnologia e possuem a mesma dotação de capital humano, a única explicação para diferenças de renda per capita entre países seria diferenças no estoque de capital per capita. Se existirem diferenças relativas ao estoque de capital per capita entre países, a taxa de retorno do capital será menor nos países com maior estoque de capital per capita (países ricos) e maior nos países com menor estoque de capital per capita (países pobres). Em um ambiente de livre mobilidade de capitais, o capital fluirá dos países ricos para os países pobres até a equalização da taxa de retorno do capital, do estoque de capital per capita e da renda per capita entre países (Acemoglu, 2009).

O modelo tem implicações para o padrão dos fluxos de capitais entre países desenvolvidos e países em desenvolvimento e para a dinâmica de acumulação de capital, crescimento econômico e consumo nos países em desenvolvimento (Obstfeld, Rogoff, 1996; Henry, 2007; Acemoglu, 2009):

i) os países desenvolvidos, onde se supõe que o capital é relativamente abundante e a taxa de retorno do capital é baixa, exportariam capital; os países em desenvolvimento, onde se supõe que o capital é relativamente escasso e a taxa de retorno do capital é alta, importariam capital;

ii) nos países em desenvolvimento, onde se supõe que a acumulação de capital é restrita pelo baixo nível de poupança doméstica, o acesso à poupança externa complementaria a poupança doméstica, estimularia a acumulação de capital e o crescimento econômico; 
iii) a possibilidade para diversificação internacional de risco permitiria desconectar flutuações do nível de consumo de flutuações do nível de produto e reduzir a volatilidade do consumo relativa à volatilidade do produto.

\subsection{Fluxos de Capitais e a Teoria do Second Best}

$\mathrm{Na}$ teoria do second best, a eliminação de uma distorção (controles de capitais) na presença de outras distorções, pode não levar a um resultado superior do ponto de vista do bem-estar (Lipsey, 2007). As distorções no mercado financeiro internacional são assimetria de informação e problemas de enforcement de contratos e as distorções nas economias domésticas são baixos níveis de desenvolvimento institucional, desenvolvimento financeiro, abertura comercial e estabilidade macroeconômica (Obstfeld, Rogoff, 1996; Eichengreen et al., 1998; Eichengreen, 2000, 2007; Edison et al., 2002; Obstfeld, 2009). Na presença de distorções, a livre mobilidade de capitais pode não resultar em alocação eficiente da poupança global e ter efeitos adversos sobre a acumulação de capital e o crescimento econômico nos países em desenvolvimento.

Eichengreen et al. (1998) e Eichengreen (2000, 2007) reconhecem que assimetria de informação, problemas de enforcement de contratos e distorções nas economias domésticas enfraquecem os pressupostos teóricos e previsões subjacentes ao modelo neoclássico, mas sugerem a possibilidade de que os fluxos de capitais podem estimular o crescimento econômico em países em desenvolvimento onde existem condições iniciais adequadas relativas a altos níveis de desenvolvimento institucional, desenvolvimento financeiro, abertura comercial e estabilidade macroeconômica, criadas por meio da realização de reformas prévias. Na ausência de reformas prévias para eliminarem distorções e criarem condições iniciais adequadas, os fluxos de capitais podem levar a crises financeiras. ${ }^{1}$

1 De acordo com Eichengreen et al. (1998, p.14):"The theoretical presumption in favor of the liberalization of domestic and international financial markets is weakened by the presence of asymmetric information and domestic distortions". Conforme Eichengreen (2007, p.10): "The bottom line is the importance of properly sequencing capital account liberalization with other policies. They need to open to trade before opening to capital flows to ensure that foreign finance flows into the right sectors. They need sound and stable monetary and fiscal policies and the more flexible exchange rate regime appropriate to an environment of open capital markets. They need to upgrade prudential supervision and corporate governance. Above all they need to enhance the informational efficiency of financial markets". Por fim, Eichengreen 
Rodrik (1998), Bhagwati (1998) e Stiglitz (2000, 2004, 2010) afirmam que, por conta da existência de assimetria de informação, mercados incompletos e comportamento irracional, os fluxos de capitais podem levar à instabilidade macroeconômica e crises financeiras, com consequências adversas para a acumulação de capital e o crescimento econômico nos países em desenvolvimento. Ademais, Rodrik e Subramanian (2009) e Stiglitz (2004) são céticos quanto à consistência teórica e viabilidade prática da realização de reformas prévias nos países em desenvolvimento para dirimirem distorções domésticas e criarem condições iniciais adequadas, de modo que os fluxos de capitais possam estimular o crescimento econômico. ${ }^{2}$

Stiglitz $(2000,2004,2010)$ desenvolve um conjunto de modelos tendo como fundamentos a existência de assimetria de informação, mercados incompletos, externalidades e comportamento irracional, do qual se apreende três resultados sobre o papel dos fluxos de capitais nos países em desenvolvimento: i) os fluxos de capitais são prócíclicos, fluem para os países em períodos de bonança e saem dos países em períodos de dificuldades; ii) os fluxos de capitais levam a maior volatilidade do consumo, do produto, da taxa de juros e da taxa de câmbio; iii) os fluxos de capitais aumentam a probabilidade de ocorrência de crises financeiras e de contágio. Stiglitz (2000, 2004) enumera quatro motivos para os fluxos de capitais desestimularem a acumulação de capital e o crescimento econômico:

i) a maior volatilidade do consumo, do produto, da taxa de juros e da taxa de câmbio aumenta o prêmio de risco que as firmas requerem para investir e desestimula o investimento. Ademais, na medida em que o investimento depende do fluxo de caixa e do balanço patrimonial, as crises podem ter efeitos particularmente adversos sobre o investimento;

ii) a maior volatilidade do produto e da taxa de juros impõe limites ao uso de financiamento via endividamento, o que tem grandes efeitos adversos, especialmente em países em desenvolvimen-

(2007, p.11) argumenta: "It is more prudent that capital account liberalization wait on the prior implementation of other reforms to avoid precipitating a crisis".

2 Conforme Rodrik e Subramanian (2009, p.124): "Finally, we have doubts with respect to the theoretical consistency and practical feasibility of the regulatory and other reforms needed to support financial globalization in the kinds of environments faced by developing nations". De acordo com Stiglitz (2004, p.60): "But certainly theory does not suggest that good governance by itself will eliminate the problems to which we have called attention. Good governance does not eliminate information imperfections, nor does it eliminate either irrational exuberance or pessimism". 
to com mercados de capitais pouco desenvolvidos. Isso leva a uma alocação de recursos menos eficiente, menor nível de produto e menor taxa de crescimento do produto;

iii) os países mantém grande quantidade de reservas em moeda estrangeira de modo a se protegerem da volatilidade dos fluxos de capitais. A manutenção dessas reservas representa uma transferência de renda líquida para o exterior, já que o custo dos empréstimos excede a remuneração das reservas, afetando adversamente o crescimento econômico;

iv) a disciplina imposta por fluxos de capitais de curto prazo pode forçar a adoção de políticas inadequadas, desestimulando o crescimento econômico. Por exemplo, os mercados financeiros focam em déficits públicos sem considerar a composição dos gastos, de modo que quando um país é forçado a cortar investimentos públicos para equilibrar o orçamento, isso desestimula o crescimento econômico.

Korinek $(2011,2012)$ desenvolve um conjunto de modelos na tradição de modelos macroeconômicos de crises que exibem dinâmica de amplificação financeira. Os fundamentos considerados são externalidades e imperfeições no mercado financeiro:

i) externalidades - fluxos de capitais criam externalidades porque mutuários individuais racionalmente ignoram os efeitos de suas decisões individuais de financiamento para a estabilidade financeira agregada. Eles assumem o risco de crises financeiras em suas economias como dado e não reconhecem que suas ações individuais contribuem para esse risco. Essas externalidades introduzem distorções em uma ampla gama de decisões de financiamento, induzindo a endividamento excessivo, a prazos excessivamente curtos e em formas excessivamente arriscadas. Como resultado, a economia padece de um nível excessivo de fragilidade financeira;

ii) imperfeição de mercado - quando investidores internacionais fornecem financiamento, eles exigem que seus empréstimos sejam explicitamente assegurados por garantias ou implicitamente assegurados por balanços patrimoniais robustos dos seus mutuários. Porém, o valor de maior parte das garantias de um país e a saúde dos balanços patrimoniais do setor privado dependem da taxa de câmbio e dos preços de ativos: melhoram em períodos de bonança quando a moeda nacional aprecia e os preços dos ativos aumentam e deterioram em períodos de dificuldades quando a moeda nacional deprecia e os preços dos ativos diminuem. 
Nessas circunstâncias, um choque adverso em um país em desenvolvimento pode levar a um ciclo de realimentação: i) depreciação cambial e declínio nos preços dos ativos; ii) deterioração dos balanços patrimoniais e diminuição do valor das garantias; iii) restrição ao financiamento externo, saída de capitais e redução do consumo e investimento; iv) saída de capitais e retração da demanda agregada levam à depreciação cambial e diminuição de preços dos ativos, realimentando o ciclo. Portanto, a amplificação financeira surge quando a economia experimenta um choque que desencadeia um ciclo de realimentação caracterizado por depreciação cambial e declínio de preços de ativos, deterioração dos balanços patrimoniais, saída de capitais e contração da atividade econômica.

O gatilho inicial para a dinâmica de amplificação financeira pode ser um choque a um dos três elementos do ciclo de realimentação: i) choque exógeno na taxa de câmbio ou preços dos ativos pode ser desencadeado por saídas de capitais ou aumento da aversão global ao risco; ii) choque exógeno sobre os balanços patrimoniais pode de ser causado por perdas inesperadas sobre o capital social ou condições de crédito mais restritivas; iii) choques adversos sobre a demanda agregada podem ser causados por declínio exógeno nas exportações ou diminuição da taxa de crescimento. Quando a economia está sujeita a amplificação financeira, os fluxos de capitais tornam-se prócíclicos, dado que as restrições ao crédito são relaxadas em períodos de bonança e apertadas em períodos de dificuldades. ${ }^{3}$

\subsection{Fluxos de Capitais e os Beneficios Indiretos}

Dell'Ariccia et al. (2008), Kose et al. (2009) e Kose et al. (2010) argumentam que o principal benefício dos fluxos de capitais para os países em desenvolvimento não seria direto na forma de captação de poupança externa para financiar a acumulação de capital, como suposto no modelo neoclássico. Os principais benefícios dos fluxos de capitais para os países em desenvolvimento seriam indiretos, na for-

3 Korinek (2012, p.98) argumenta: "Capital flows to emerging market economies create externalities that make the affected economies more vulnerable to financial fragility and crisis". Ademais: "When the economy is hit by an adverse shock and experiences financial amplification, the resulting credit crunch forces domestic agents to temporarily cut back on investment. This reduces growth for the duration of the crisis episode and leads to a permanently lower path of output" (Korinek, 2011, p.555). 
ma de estímulo ao desenvolvimento institucional, desenvolvimento financeiro e disciplina macroeconômica. Esses benefícios indiretos, por sua vez, estimulariam o crescimento da produtividade e o crescimento econômico. No entanto, para a concretização dos benefícios indiretos dos fluxos de capitais, seria necessária a existência de condições iniciais adequadas nos países em desenvolvimento relativas a altos níveis de desenvolvimento institucional, desenvolvimento financeiro, estabilidade macroeconômica, abertura comercial e capital humano. Na ausência de condições iniciais adequadas, os fluxos de capitais poderiam resultar em instabilidade macroeconômica e crises financeiras. ${ }^{4}$

Ademais, diferentes categorias de fluxos de capitais teriam efeitos distintos sobre o crescimento econômico. A distinção é entre Fluxo Equity (Investimento Externo Direto + Investimento de Portfólio Equity) e Fluxo Debt (Outros Investimentos + Investimento de Portfólio Debt). Os benefícios indiretos estariam associados especialmente a Fluxo Equity: 'Flows that have equity-like features - that is, FDI and portfolio equity flows - are not only presumed to be more stable and less prone to reversals, but are also believed to bring with them many of the indirect benefits of financial globalization' (Kose et al., 2009, p.30). Entre Fluxo Equity, destaca-se Investimento Externo Direto: 'There is a strong presumption in theory that FDI should yield more benefits than other types of financial flows because, in addition to augmenting the domestic capital stock, it has a positive impact on productivity through transfers of technology and managerial expertise' (Kose et al., 2009, p. 30). Fluxo Debt, por sua vez, seria pró-cíclico, volátil e não estaria claramente associado a benefícios indiretos. ${ }^{5}$

${ }^{4}$ Conforme Kose et al. (2009, p.40): "A key component of our argument is that it is not just the capital inflows themselves, but what comes along with the capital inflows, that drives the benefits of financial globalization for developing countries. These collateral benefits could include development of the domestic financial sector, improvements in institutions (defined broadly to include governance, the rule of law, and so on), better macroeconomic policies, and so on. These collateral benefits then result in higher growth, usually through gains in allocative efficiency". Kose et al. (2009, p.42) reconhece a circularidade no argumento: "There is a great deal of similarity between the list of collateral benefits of financial integration and the list of threshold conditions. Indeed, the discussion highlights the difficulties involved in trying to make strong causal statements about the effects of financial integration" (Kose et al., 2009, p.42). Ademais: "Full-fledged opening of the capital account in the absence of essential supporting conditions can vitiate the realization of any benefits, while making a country more vulnerable to sudden stops of capital flows and the financial crisis" (Kose et al., 2009, p.43).

5 Borensztein et al. (1998), Durham (2004), Alfaro et al. (2004) e Alfaro et al. (2009) sugerem que Investimento Externo Direto pode estimular o crescimento econômico por meio da acumulação de capital físico, acumulação de capital humano e crescimento da produti- 


\subsection{Fluxos de Capitais e a Taxa Real de Câmbio}

Rodrik e Subramanian (2009) distinguem entre economias em que a acumulação de capital é restrita pela ausência de poupança e economias as quais a acumulação de capital é restrita pela ausência de oportunidades de investimento. Argumentam que a acumulação de capital e o crescimento econômico nos países em desenvolvimento são constrangidos pela ausência de oportunidades de investimento. A ausência de oportunidades de investimento é explicada por distorções relativas ao ambiente institucional (pobre proteção ao direito de propriedade, risco de expropriação, fraco enforcement de contratos), implicando imperfeita apropriabilidade do retorno social do investimento. As distorções relativas ao ambiente institucional, aliadas a falhas de mercado (externalidades de informação e coordenação), seriam especialmente relevantes no setor de bens comercializáveis.

Nas economias caracterizadas por distorções relativas ao ambiente institucional, os fluxos de capitais levariam à substituição da poupança doméstica pela poupança externa, aumento do consumo e efeito nulo sobre o investimento. Ademais, os fluxos de capitais levariam à apreciação da taxa real de câmbio, o que deprimiria ainda mais a lucratividade no setor de bens comercializáveis, levando a possíveis efeitos adversos sobre o crescimento econômico. Em resumo, Rodrik e Subramanian (2009) argumentam que os fluxos de capitais para os países em desenvolvimento não estimulam a acumulação de capital, levam à apreciação da taxa real de câmbio, diminuem a lucratividade no setor de bens comercializáveis e têm consequências adversas para o crescimento econômico. ${ }^{6}$

vidade. Conforme Alfaro et al. (2004, p.90): "The rationale for increased efforts to attract more FDI stems from the belief that FDI has several positive effects which include productivity gains, technology transfers, the introduction of new processes, managerial skills, and knowhow in the domestic market, employee training, international production networks, and access to markets". Stiglitz (2004) reconhece os benefícios associados a Investimento Externo Direto, na forma de transferência de tecnologias avançadas, práticas administrativas sofisticadas, treinamento da força de trabalho e acesso a mercados externos, mas pondera que quando resultado de privatizações ou direcionado para exploração de recursos naturais, pode ter efeitos adversos sobre o crescimento econômico nos países em desenvolvimento.

6 Conforme Rodrik e Subramanian (2009, p.112): “We argue that developing economies are as or more likely to be investment-constrained than saving-constrained and that the effect of foreign finance is often to aggravate this investment constraint by appreciating the real exchange rate and reducing profitability and investment opportunities in the traded goods sector, which have adverse long-run growth consequences". Sugerem que a distinção entre tipos de fluxos de capitais é menos relevante nesse contexto, dado que todos os tipos de fluxos podem ter o mesmo efeito sobre a taxa real de câmbio. 
Por fim, o paradigma de Salter (1959), Swan (1960), Corden (1960) e Dornbusch (1974) fornece um arcabouço que permite compreender como os fluxos de capitais para os países em desenvolvimento podem causar apreciação da taxa real de câmbio. Um aumento nos fluxos de capitais aumenta os salários reais, o que causa um aumento na demanda doméstica e um aumento nos preços dos bens não comercializáveis em relação aos preços dos bens comercializáveis, os quais são determinados exogenamente. Como a taxa real de câmbio é geralmente definida como os preços domésticos de bens não comercializáveis em relação aos preços dos bens comercializáveis, um aumento no preço relativo dos bens não comercializáveis corresponde a uma apreciação da taxa real de câmbio.

\subsection{As Evidências Econométricas}

Os trabalhos estimam equações de crescimento para amostras de países, incluindo entre as variáveis explanatórias medidas de fluxos de capitais. O Quadro Al em apêndice apresenta descrição detalhada dos trabalhos consultados.

Para os trabalhos que utilizam amostra composta por países em desenvolvimento, os resultados sugerem: i) Bosworth e Collins (1999) não encontram evidências de que Fluxo Total de Capitais e Investimento de Portfólio estimulam o crescimento econômico, Reisen e Soto (2001) não encontram evidências de que Créditos Bancários e Comerciais e Investimento de Portfólio Debt estimulam o crescimento econômico, Borensztein et al. (1998) e Herzer et al. (2008) não encontram evidências de que Investimento Externo Direto estimula o crescimento econômico; ii) Bosworth e Collins (1999) encontram evidências de que Investimento Externo Direto estimula o crescimento econômico e Reisen e Soto (2001) encontram evidências de que Investimento Externo Direto e Investimento de Portfólio Equity estimulam o crescimento econômico; iii) Borensztein et al. (1998) encontram evidências de que Investimento Externo Direto estimula o crescimento econômico, mas apenas em países com nível adequado de capital humano; iv) Prasad et al. (2007) encontram evidências de que poupança externa desestimula o crescimento econômico. 
Para os trabalhos que utilizam amostra composta por países desenvolvidos e em desenvolvimento os resultados indicam: i) Durham (2004), Alfaro et al. (2004), Alfaro et al. (2009) e Carkovic e Levine (2005) não encontram evidências de que Investimento Externo Direto estimula o crescimento econômico; ii) Durham (2004) encontra evidências frágeis de que Investimento Externo Direto e Investimento de Portfólio Equity estimulam o crescimento econômico apenas em países com níveis adequados de desenvolvimento institucional e financeiro, enquanto Alfaro et al. (2004) e Alfaro et al. (2009) encontram evidências de que Investimento Externo Direto estimula o crescimento econômico apenas em países com nível adequado de desenvolvimento financeiro; iii) Durham (2004) não encontra evidências de que o efeito de Investimento Externo Direto e Investimento de Portfólio Equity sobre o crescimento econômico depende dos níveis de abertura comercial e capital humano, enquanto Alfaro et al. (2004) não encontram evidências de que o efeito de Investimento Externo Direto sobre o crescimento econômico depende do nível de capital humano; já Alfaro et al. (2009) não encontram evidências de que o efeito de Investimento Externo Direto sobre o crescimento econômico depende dos níveis de desenvolvimento institucional e capital humano e Carkovic e Levine (2005) não encontram evidências de que o efeito de Investimento Externo Direto sobre o crescimento econômico depende dos níveis de desenvolvimento econômico, desenvolvimento financeiro, abertura comercial e capital humano.

Essa síntese sugere a ausência de consenso quanto a evidências sistemáticas de que fluxos de capitais estimulam o crescimento econômico. Existem limitações em cada trabalho e diferenças entre os trabalhos, ambas relativas às seguintes dimensões metodológicas: amostra de países, período de análise, método econométrico, medidas de fluxos de capitais e hipóteses de não linearidades testadas.

Essas limitações em cada trabalho e diferenças entre os trabalhos, ambas relativas a esses aspectos metodológicos, podem explicar a diversidade de resultados reportados na literatura. Dadas as limitações metodológicas dos trabalhos, diferenças metodológicas entre os trabalhos e diversidade de resultados reportados, este trabalho contribui para a literatura econométrica acerca das relações entre fluxos de capitais e crescimento econômico nos países em desenvolvimento ao apresentar em um único trabalho arcabouço empírico unificado 
que permite contornar as limitações metodológicas presentes na literatura relativas a cinco aspectos:

i) os dados abrangem o período 1980-2004. Dentre os estudos para amostra de países em desenvolvimento, o que utiliza dados mais atualizados é Prasad et al. (2007), os quais abrangem o período 1970-2004. Em todos os estudos para amostras compostas por países desenvolvidos e em desenvolvimento os dados abrangem até a primeira metade da década de 1990;

ii) a amostra é composta de 83 países em desenvolvimento. Dentre os estudos para amostra de países em desenvolvimento, o que utiliza a maior amostra é Borensztein et al. (1998), 69 países. Dentre os trabalhos para amostra de países desenvolvidos e em desenvolvimento, o que utiliza a maior amostra é Durham (2004), 80 países;

iii) utiliza sete medidas de fluxos de capitais, agregadas e desagregadas. Dentre os estudos para amostra de países em desenvolvimento, Reisen e Soto (2001) utilizam o maior número de medidas, quatro. Dentre os trabalhos para amostra de países desenvolvidos e em desenvolvimento, Durham (2004) utiliza maior número de medidas, duas;

iv) o método econométrico controla para endogeneidade. Dentre os trabalhos para amostra de países em desenvolvimento, apenas Reisen e Soto (2001) utilizam método econométrico que controla para endogeneidade. Dentre os estudos para amostra de países desenvolvidos e em desenvolvimento, apenas Carkovic e Levine (2005) utilizam método econométrico que controla para endogeneidade;

v) testa se o efeito marginal dos fluxos de capitais sobre o crescimento econômico depende dos níveis de desenvolvimento institucional, desenvolvimento financeiro, abertura comercial, estabilidade macroeconômica e capital humano. Dentre os estudos para amostra de países em desenvolvimento, Borensztein et al. (1998) testam uma hipótese de não linearidade. Dentre os estudos para amostras de países desenvolvidos e em desenvolvimento cabe destacar Carkovic e Levine (2005). 


\section{Procedimentos Metodológicos}

\subsection{Especificação do Modelo}

A equação de crescimento está especificada na forma de um modelo dinâmico de dados em painel, conforme Islam (1995), Caselli et al. (1996) e Bond et al. (2001):

$$
\begin{aligned}
& y_{i, t}-y_{i, t-1}=(\alpha-1) y_{i, t-1}+x_{i, t}^{\prime} \beta+u_{i, t} \quad i=1,2, \ldots, N \text { e } t=2,3, \ldots, T \\
& u_{i, t}=\gamma_{t}+\eta_{i}+v_{i, t}
\end{aligned}
$$

Onde $y_{i, t}$ é o logaritmo natural do PIB per capita para o país í no período $t, y_{i, t-1}$, é o logaritmo natural do PIB per capita para o país $i$ no período $t-1, x_{i, t}$, é um vetor-linha de possíveis determinantes do estado estacionário para o país $i$ no período $t$ e $x_{i, t}$ é o termo de erro. O termo $\gamma_{t}$ varia ao longo do tempo, é constante entre os países e capta choques comuns a todos os países e não controlados pelas variáveis em $x_{i, t}$. O termo $\eta_{i}$ varia entre os países, é constante ao longo do tempo e controla para determinantes do crescimento não incluídos em $x_{i, t}$. O termo $v_{i, t}$ é o erro, varia entre os países e ao longo do tempo. As informações utilizadas para a estimação das equações de crescimento estão organizadas em cinco intervalos de cinco anos não sobrepostos (1980-1984, 1985-1989, 1990-1994, 1995-1999, 2000-2004) e o painel é desbalanceado.

A variável dependente é a taxa de crescimento do PIB per capita real, média anual para cada período de cinco anos. As variáveis explanatórias são: i) PIB Inicial e Capital Humano, níveis no ano inicial de cada período de cinco anos; ii) Investimento e População, médias anuais para cada período de cinco anos; iii) Lei \& Ordem, Comércio, Crédito, Governo e Inflação, médias anuais para cada período de cinco anos. Serão incluídas como variáveis explanatórias sete medidas de fluxos de capitais: i) Conta Corrente (fluxo líquido de capitais/ poupança externa), média para cada período de cinco anos; ${ }^{7}$ ii) Fluxo Total de Capitais (Investimento Externo Direto + Investimento de Portfólio + Outros Investimentos), entrada líquida, média para cada período de cinco anos; iii) Investimento Externo Direto, entrada líquida, média para cada período de cinco anos; iv) Investimento de

7 O valor do saldo em conta corrente do balanço de pagamentos foi multiplicado por -1, de modo que um valor positivo significa entrada líquida de capitais/importação de poupança externa. 
Portfólio, entrada líquida, média para cada período de cinco anos; v) Outros Investimentos, entrada líquida, média para cada período de cinco anos; vi) Fluxo Equity (Investimento Externo Direto + Investimento de Portfólio Equity), entrada líquida, média para cada período de cinco anos; vii) Fluxo Debt (Outros Investimentos + Investimento de Portfólio Debt), entrada líquida, média para cada período de cinco anos. A Tabela Al em Apêndice apresenta a definição de todas as variáveis.

Arellano e Bover (1995) e Blundell e Bond (1998) desenvolveram um estimador GMM para modelos dinâmicos de dados em painel cuja ideia básica consiste em estimar um sistema de equações compreendendo todas as $T$ - 2 equações em primeira diferença e todas as $T-2$ equações em nível, correspondendo aos períodos $3, \ldots, T$ para os quais instrumentos são observados. Os instrumentos para a equação em primeira diferença são os valores defasados em nível das variáveis explanatórias. Os instrumentos para a equação em nível são os valores defasados em primeira diferença das variáveis explanatórias. Esse estimador é denominado System GMM e será utilizado para a estimação de todas as equações de crescimento apresentadas neste trabalho. Conforme Bond et al. (2001, p.4): 'We recommend this system GMM estimator for consideration in subsequent empirical growth research'.

A variável PIB Inicial será considerada fracamente exógena em todas as equações estimadas. As variáveis Capital Humano, Investimento, População, Lei \& Ordem, Comércio, Crédito, Governo, Inflação, Conta Corrente, Fluxo Total de Capitais, Investimento Externo Direto, Investimento de Portfólio, Outros Investimentos, Fluxo Equity, Fluxo Debt e todas as variáveis de interação serão consideradas endógenas em todas as equações estimadas. As dummies temporais serão consideradas estritamente exógenas em todas as equações estimadas.

Como é padrão no contexto de System GMM, todas as variáveis explanatórias serão instrumentalizadas: i) as variáveis fracamente exógenas e as variáveis endógenas serão instrumentalizadas por seus valores defasados, em nível e em primeira diferença; ii) as variáveis estritamente exógenas serão instrumentalizadas por seus próprios valores. 
A consistência do estimador GMM depende da validade das condições de momento. Serão considerados três testes de especificação: i) o Hansen Test e o Diff. Hansen Test, que testam a hipótese nula de validade das condições de momento; ii) o $A R(2)$, que testa a hipótese nula de inexistência de correlação serial de segunda ordem no termo de erro. Três aspectos justificam a utilização do estimador System GMM: i) explorar a natureza temporal da relação entre as variáveis explanatórias e a taxa de crescimento do PIB per capita; ii) controlar para efeitos específicos a cada país não observáveis e choques específicos a cada período comuns a todos os países; iii) levar em consideração a possível endogeneidade dos fluxos de capitais. ${ }^{8}$ As estimações serão realizadas por meio do software Stata 11, utilizando o comando xtabond2 desenvolvido por Roodman (2009).

A amostra é composta de 83 países em desenvolvimento e foi selecionada de acordo com a disponibilidade de informações: Argentina, Brasil, Chile, China, Colômbia, Egito, Hong Kong, Índia, Indonésia, Israel, Jordânia, Coréia, Malásia, México, Paquistão, Peru, Filipinas, Arábia Saudita, Singapura, África do Sul, Tailândia, Turquia, Venezuela, Argélia, Bahrein, Bangladesh, Benin, Bolívia, Botsuana, Burkina Faso, Camarões, Chade, Dem. Rep. do Congo, Rep. do Congo, Costa Rica, Costa do Marfim, República Dominicana, Equador, El Salvador, Etiópia, Fiji, Garbon, Gana, Guatemala, Guiné, Haiti, Honduras, Irã, Jamaica, Quênia, Kuwait, Líbano, Líbia, Madagáscar, Malawi, Mali, Malta, Maurícius, Marrocos, Birmânia, Nepal, Nicarágua, Níger, Nigéria, Omã, Panamá, Papua Nova Guiné, Paraguai, Catar, Ruanda, Senegal, Sri Lanka, Sudão, Suazilândia, Síria República Árabe, Tanzânia, Togo, Trindade e Tobago, Tunísia, Uganda, Emirados Árabes Unidos, Uruguai e Zâmbia.

\subsection{Estratégia Empírica}

Para testar o efeito marginal dos fluxos de capitais sobre o crescimento do PIB per capita, serão estimadas equações de crescimento incluindo entre as variáveis explanatórias medidas de fluxos de

\footnotetext{
8 Como argumentam Borensztein et al. (1998), Alfaro et al. (2004) e Alfaro et al. (2009), é provável que países com trajetórias de crescimento mais robustas atraiam mais fluxos de capitais, ou seja, os fluxos de capitais aumentariam com o aumento na taxa de crescimento, de modo que fluxos de capitais seriam endógenos em equações de crescimento, tornando necessário um procedimento de variáveis instrumentais.
} 
capitais. Se os coeficientes associados às variáveis Conta Corrente, Fluxo Total de Capitais, Investimento Externo Direto, Investimento de Portfólio, Outros Investimentos, Fluxo Equity e Fluxo Debt forem positivos e estatisticamente significativos, existem evidências de que os fluxos de capitais estimulam o crescimento do PIB per capita.

Para testar se o efeito marginal dos fluxos de capitais sobre o crescimento do PIB per capita depende dos níveis de desenvolvimento institucional, desenvolvimento financeiro, abertura comercial, estabilidade macroeconômica e capital humano, serão estimadas equações incluindo entre as variáveis explanatórias um termo de interação linear entre Conta Corrente, Fluxo Total de Capitais, Investimento Externo Direto, Investimento de Portfólio, Outros Investimentos, Fluxo Equity e Fluxo Debt $\left(F C_{i, t}\right)$ e cada variável Lei \& Ordem, Crédito, Comércio, Governo, Inflação e Capital Humano $\left(C D_{i, t}\right)$ :

$$
\theta_{1} \mathrm{FC}_{i, t}+\theta_{2} \mathrm{FC}_{i, t}{ }^{*} \mathrm{CD}_{i, t}+\theta_{3} \mathrm{CD}_{i, t}
$$

O efeito marginal dos fluxos de capitais $\left(F C_{i, t}\right)$ sobre o crescimento do PIB per capita depende das condições domésticas $\left(C D_{i, t}\right)$ e é dado por:

$$
\partial \Delta y_{i, t} / \partial F C_{i, t}=\theta_{1}+\theta_{2} C D_{i, t}
$$

Para ilustrar a interpretação dos resultados, tomemos um exemplo: $F C_{i, t}$ é Fluxo Total de Capitais e $C D_{i, t}$ é Lei \& Ordem, então se $\theta_{1}<0$ e $\theta_{2}>0$, ambos estatisticamente significativos, existe evidência de que o efeito marginal do Fluxo Total de Capitais sobre o crescimento do PIB per capita depende do nível de desenvolvimento institucional e de que o Fluxo Total de Capitais estimula o crescimento do PIB per capita, apenas a partir de certo nível de desenvolvimento institucional.

\section{Fluxos de Capitais e Crescimento Econômico: Evidências Econométricas}

São consideradas quatro especificações para a equação de crescimento: i) PIB Inicial, Capital Humano, População, Investimento e medidas de fluxos de capitais; ii) PIB Inicial, Capital Humano, 
População e medidas de fluxos de capitais; iii) PIB Inicial, Capital Humano, População, Investimento e um termo de interação linear; iv) PIB Inicial, Capital Humano, População e um termo de interação linear. Foram estimadas 88 equações de crescimento, apresentadas nas Tabelas A2 a A8 em Apêndice.

É possível destacar cinco regularidades: i) os testes $A R(2)$, Hansen Test e Diff. Hansen Test não rejeitam as especificações para as equações estimadas; ii) há evidência de convergência condicional em 80 equações estimadas, dentre 88 ; iii) há evidência de que Capital Humano estimula o crescimento do PIB per capita em 85 equações estimadas, dentre 88; iv) há evidência de que Investimento estimula o crescimento do PIB per capita em 29 equações estimadas, dentre 44; v) há evidência de que População desestimula o crescimento do PIB per capita em 15 equações estimadas, dentre 88 .

\subsection{Fluxos de Capitais e Crescimento Econômico}

A Tabela A2 em Apêndice apresenta resultados de regressões que testam a relação entre fluxos de capitais e crescimento do PIB per capita.

O coeficiente associado à variável Conta Corrente é negativo e estatisticamente significativo nas equações apresentadas nas colunas $1 \mathrm{e}$ 8. Portanto, as evidências sugerem que a poupança externa desestimula o crescimento do PIB per capita nos países em desenvolvimento. Esses resultados são coerentes com os de Prasad et al. (2007) para cross section, método OLS e 56 países, que sugerem como explicação a existência de níveis inadequados de desenvolvimento institucional e financeiro nos países em desenvolvimento. ${ }^{9}$

9 Para testar o efeito de "importação de poupança externa" em relação à "exportação de poupança externa", sobre o crescimento econômico, o valor do saldo em conta corrente foi transformado em uma variável binária e foram estimadas duas equações com especificações equivalentes àquelas apresentadas nas colunas 1 e 8 da Tabela A2. Como o valor do saldo em conta corrente foi multiplicado por -1, significa que foi atribuído valor 1 para um saldo positivo em conta corrente (importação de poupança externa) e valor 0 para um saldo negativo em conta corrente (exportação de poupança externa). Os resultados, não reportados, sugerem fracamente que países que importam poupança externa (exportam poupança externa) crescem menos (crescem mais) relativamente a países que exportam poupança externa (importam poupança externa) e são coerentes com aqueles apresentados nas colunas 1 e 8 da Tabela A2. 
Os coeficientes associados às variáveis Fluxo Total de Capitais, Fluxo Equity, Fluxo Debt, Investimento Externo Direto, Investimento de Portfólio e Outros Investimentos não são estatisticamente significativos. Ou seja, não há evidências de que Fluxo Total de Capitais, Fluxo Equity, Fluxo Debt, Investimento Externo Direto, Investimento de Portfólio e Outros Investimentos estimulam o crescimento do PIB per capita nos países em desenvolvimento. ${ }^{10}$

Esses resultados são coerentes com os de Borensztein et al. (1998) para Investimento Externo Direto, Bosworth e Collins (1999) para Fluxo Total de Capitais e Investimento de Portfólio, Reisen e Soto (2001) para Investimento de Portfólio Debt e Créditos Comerciais e Bancários e Herzer et al. (2008) para Investimento Externo Direto, considerando amostras de países em desenvolvimento e com os de Durham (2004), Alfaro et al. (2004), Carkovic e Levine (2005) e Alfaro et al. (2009) para Investimento Externo Direto, considerando amostras de países desenvolvidos e em desenvolvimento. Conforme Eichengreen (2000, 2007), Prasad et al. (2007), Dell'Ariccia et al. (2008), Kose et al. (2009) e Kose et al. (2010), possíveis explicações para o efeito adverso da poupança externa sobre o crescimento do PIB per capita e para a ausência de relação estatisticamente significativa entre as medidas de fluxos de capitais e o crescimento do PIB per capita seriam níveis inadequados de desenvolvimento institucional, desenvolvimento financeiro, abertura comercial, estabilidade macroeconômica e capital humano nos países em desenvolvimento.

Essas possíveis explicações sugerem relações não lineares entre as medidas de fluxos de capitais e o crescimento do PIB per capita, as quais são testadas e apresentadas nas subseções seguintes.

\subsection{Fluxos de Capitais, Ambiente Institucional e Crescimento Econômico}

A Tabela A3 em Apêndice apresenta resultados de regressões que testam se o efeito marginal dos fluxos de capitais sobre o crescimento do PIB per capita depende do nível de desenvolvimento institucional.

${ }^{10}$ Foram estimadas 14 equações conforme as especificações apresentadas na Tabela A2, mas incluindo as sete medidas de fluxos de capitais com uma defasagem. Os resultados, não reportados, sugerem que não há relação estatisticamente significativa entre as sete categorias de fluxos de capitais defasadas e crescimento econômico. 
Não há equação estimada para qual o coeficiente associado a uma medida de fluxos de capitais é negativo e o coeficiente associado a uma variável de interação é positivo, ambos estatisticamente significativos.

$\mathrm{Na}$ Equação da coluna 6, o coeficiente associado à variável Investimento de Portfólio é positivo e estatisticamente significativo e o coeficiente associado à variável Investimento de Portfólio x Lei \& Ordem é negativo e estatisticamente significativo, indicando que o efeito marginal do Investimento de Portfólio sobre o crescimento do PIB per capita depende do nível de desenvolvimento institucional e diminui com o aumento no nível de desenvolvimento institucional.

Portanto, as evidências não corroboram a hipótese de que o efeito marginal dos fluxos de capitais sobre o crescimento do PIB per capita depende do nível de desenvolvimento institucional e de que os fluxos de capitais estimulam o crescimento do PIB per capita, apenas em países com instituições desenvolvidas. Na literatura consultada, não há trabalho para amostra de países em desenvolvimento que testa se o efeito marginal dos fluxos de capitais sobre o crescimento do PIB per capita depende do nível de desenvolvimento institucional.

Considerando trabalhos para amostras de países desenvolvidos e em desenvolvimento, os resultados expostos são coerentes com os de Alfaro et al. (2009) para Investimento Externo Direto e distintos dos de Durham (2004), que apresenta evidências frágeis de que Investimento Externo Direto estimula o crescimento do PIB per capita apenas em países com níveis adequados de desenvolvimento institucional.

\subsection{Fluxos de Capitais, Desenvolvimento Financeiro e Crescimento Econômico}

A Tabela A4 em Apêndice apresenta resultados de regressões que testam se o efeito marginal dos fluxos de capitais sobre o crescimento do PIB per capita depende do nível de desenvolvimento financeiro. Em nenhuma das equações estimadas o coeficiente associado a uma medida de fluxos de capitais é negativo e o coeficiente associado a uma variável de interação é positivo, ambos estatisticamente significativos. Nas Equações das colunas 6 e 13, o coeficiente asso- 
ciado à variável Investimento de Portfólio é positivo e estatisticamente significativo e o coeficiente associado à variável Investimento de Portfólio x Crédito é negativo e estatisticamente significativo, sugerindo que o efeito marginal do Investimento de Portfólio sobre o crescimento do PIB per capita depende do nível de desenvolvimento financeiro e diminui com o aumento no nível de desenvolvimento financeiro.

Desse modo, as evidências não corroboram a hipótese de que o efeito marginal dos fluxos de capitais sobre o crescimento do PIB per capita depende do nível de desenvolvimento financeiro e de que os fluxos de capitais estimulam o crescimento do PIB per capita, apenas em países com sistema financeiro desenvolvido. Na literatura consultada, não há trabalho para amostra composta por países em desenvolvimento, que testa se o efeito marginal dos fluxos de capitais sobre o crescimento do PIB per capita depende do nível de desenvolvimento financeiro.

Com relação aos trabalhos para amostras compostas por países desenvolvidos e em desenvolvimento, os resultados apresentados são coerentes com os de Carkovic e Levine (2005) para Investimento Externo Direto e distintos dos de Durham (2004), Alfaro et al. (2004) e Alfaro et al. (2009), que apresentam evidências de que Investimento Externo Direto estimula o crescimento do PIB per capita, mas apenas em países com níveis adequados de desenvolvimento financeiro.

\subsection{Fluxos de Capitais, Abertura Comercial e Crescimento Econômico}

A Tabela A5 em Apêndice apresenta resultados de regressões que testam se o efeito marginal dos fluxos de capitais sobre o crescimento do PIB per capita depende do nível de abertura comercial.

Dentre 14 equações estimadas, em nenhuma o coeficiente associado a uma medida de fluxos de capitais é negativo e o coeficiente associado a uma variável de interação é positivo, ambos estatisticamente significativos. Nas Equações das colunas 6 e 13, o coeficiente associado à variável Investimento de Portfólio é positivo e estatisticamente significativo e o coeficiente associado à variável Investimento de Portfólio x Comércio é negativo e estatisticamente significativo, 
sugerindo que o efeito marginal do Investimento de Portfólio sobre o crescimento do PIB per capita depende do nível de abertura comercial e diminui com o aumento no nível de abertura comercial. Esses resultados não corroboram a hipótese de que o efeito marginal dos fluxos de capitais sobre o crescimento do PIB per capita depende do nível de abertura comercial e de que os fluxos de capitais estimulam o crescimento do PIB per capita apenas em países abertos ao comércio internacional. $\mathrm{Na}$ literatura consultada, não há trabalho para países em desenvolvimento que testa se o efeito marginal dos fluxos de capitais sobre o crescimento do PIB per capita depende do nível de abertura comercial.

Considerando os trabalhos para amostras compostas por países desenvolvidos e em desenvolvimento, os resultados apresentados são coerentes com os de Durham (2004) e Carkovic e Levine (2005), que não encontram evidências de que o efeito marginal de Investimento Externo Direto sobre o crescimento do PIB per capita depende do nível de abertura ao comércio internacional.

\subsection{Fluxos de Capitais, Política Macroeconômica e Crescimento} Econômico

As Tabelas A6 e A7 em Apêndice apresentam resultados de regressões que testam se o efeito marginal dos fluxos de capitais sobre o crescimento do PIB per capita depende do ambiente macroeconômico.

Em nenhuma das equações estimadas o coeficiente associado a uma medida de fluxos de capitais é negativo e o coeficiente associado a uma variável de interação é negativo, ambos estatisticamente significativos. Portanto, as evidências não corroboram a hipótese de que o efeito marginal dos fluxos de capitais sobre o crescimento do PIB per capita depende do ambiente macroeconômico e de que os fluxos de capitais estimulam o crescimento do PIB per capita, apenas em países com política monetária e fiscal austeras. Na literatura consultada, não há trabalho que testa se o efeito marginal dos fluxos de capitais sobre o crescimento do PIB per capita depende do ambiente macroeconômico. 


\subsection{Fluxos de Capitais, Capital Humano e Crescimento Econômico}

A Tabela A8 em Apêndice apresenta resultados de regressões que testam se os efeitos marginais do Investimento Externo Direto e do Fluxo Equity sobre o crescimento do PIB per capita dependem do nível de capital humano. Dentre as 4 equações estimadas não há alguma para a qual o coeficiente associado a uma medida de fluxos de capitais é negativo e o coeficiente associado a uma variável de interação é positivo, ambos estatisticamente significativos. Portanto, não há evidências de que os efeitos marginais do Fluxo Equity e do Investimento Externo Direto sobre o crescimento do PIB per capita dependem do nível de capital humano e de que Fluxo Equity e Investimento Externo Direto estimulam o crescimento do PIB per capita, apenas em países com alto nível de capital humano.

Considerando os trabalhos para amostras compostas por países em desenvolvimento, os resultados apresentados são distintos dos de Borensztein et al. (1998), que apresentam evidências de que Investimento Externo Direto estimula o crescimento do PIB per capita, mas apenas em países com um nível adequado de capital humano. Com referência aos trabalhos para amostras de países desenvolvidos e em desenvolvimento, os resultados apresentados são coerentes com os de Durham (2004), Alfaro et al. (2004), Carkovic e Levine (2005) e Alfaro et al. (2009) para Investimento Externo Direto.

\section{Considerações Finais}

Este trabalho realiza uma ampla investigação econométrica acerca das relações entre fluxos de capitais e crescimento econômico nos países em desenvolvimento. Os procedimentos metodológicos contribuem para a literatura em aspectos relevantes: i) utiliza-se abordagem econométrica que leva em consideração a possível endogeneidade dos fluxos de capitais; ii) faz-se uso de uma ampla amostra de países em desenvolvimento durante longo período; iii) utiliza-se um amplo conjunto de medidas de fluxos de capitais; e iv) testa o efeito marginal dos fluxos de capitais sobre o crescimento econômico e se esse efeito marginal depende de um conjunto de características políticas, institucionais e econômicas nos países da amostra. 
Encontramos dois conjuntos de resultados:

i) as evidências sugerem que a poupança externa desestimula o crescimento econômico nos países em desenvolvimento. Ademais, não existem evidências de que o efeito marginal da poupança externa sobre o crescimento econômico nos países em desenvolvimento depende dos níveis de desenvolvimento institucional, desenvolvimento financeiro, abertura comercial e estabilidade macroeconômica nos países da amostra;

ii) não existem evidências de que Fluxo Total de Capitais, Fluxo Equity, Fluxo Debt, Investimento Externo Direto, Investimento de Portfólio e Outros Investimentos estimulam o crescimento econômico nos países em desenvolvimento. Ademais, não existem evidências de que o efeito marginal de Fluxo Total de Capitais, Fluxo Equity, Fluxo Debt, Investimento Externo Direto, Investimento de Portfólio e Outros Investimentos sobre o crescimento econômico nos países em desenvolvimento depende dos níveis de desenvolvimento institucional, desenvolvimento financeiro, abertura comercial, estabilidade macroeconômica e capital humano nos países da amostra.

A literatura teórica acerca das relações entre fluxos de capitais e crescimento econômico suscita possíveis explicações para esses resultados. Bhagwati (1998), Rodrik (1998), Rodrik e Subramanian (2009), Stiglitz (2000, 2004, 2010) e Korinek (2011, 2012) são céticos quanto à possibilidade de benefícios dos fluxos de capitais para os países em desenvolvimento e argumentam que esses fluxos estão associados a crises financeiras e apreciação cambial, com efeitos adversos para o crescimento econômico. Por fim, o reconhecimento de que os fluxos de capitais para os países em desenvolvimento podem levar a crises financeiras e apreciação cambial explica a legitimidade dada pelo FMI à utilização, em última instância, de controles de capitais (Ostry et al., 2011).

\section{Referências}

ACEMOGLU, D. Introduction to Modern Economic Growth. New Jersey: Princeton University Press, 2009. ALFARO, L.; KALEMLI-OZCAN, S.; SAYEK, S. FDI, Productivity and Financial Development. World Economy, Vol. 32, n 1 , p.111-135, 2009.

ALFARO, L.; CHANDA, A.; KALEMLI-OZCAN, S.; SAYEK, S. FDI and Economic Growth: the Role of Local Financial Markets. Journal of International Economics, Vol. 64, nº 1, p.89-112, 2004. 
ALVAREZ, J.; ARELlANO, M. The Time Series and Cross-Section Asymptotics of Dynamic Panel Data Estimators. Econometrica, Vol. 71, nº 4, p. 1121-1159, 2003.

ARELLANO, M.; BOND, S. Some Tests of Specification for Panel Data: Monte Carlo Evidence and an Application to Employment Equations. Review of Economic Studies, Vol.58, nº 2, p.277-297, 1991.

ARELLANO, M.; BOVER, O. Another Look at the Instrumental-Variable Estimation of Error-Components Models. Journal of Econometrics, Vol.68, p.29-51, 1995.

BARRO, R. J.; LEE, J. W. A New Data Set of Educational Attainment in the World, 1950-2010. National Bureau of Economic Research, Working Paper n 15902, 2010.

BHAGWATI, J. The Capital Myth: The Difference Between Trade in Widgets and Dollars. Foreign Affairs, Vol. 77, n 3, p. 7-12, 1998.

BLUNDELL, R.; BOND, S. Initial conditions and moment restrictions in dynamic panel data models. Journal of Econometrics, Vol.87, p.115-143, 1998.

BOND, S.; HOEFFLER, A.; TEMPLE, J. GMM Estimation of Empirical Growth Models. University of Oxford, The Institute for Fiscal Studies, Working Paper $n^{\circ} 21,2001$.

BORENSZTEIN, E.; GREGÓRIO, J; LEE, J. W. How does Foreign Direct Investment Affect Economic Growth? Journal of International Economics, Vol. 45, n⿳ 1, p.115-135, 1998.

BOSWORTH, B.; COLlinS, S. M. Capital Inflows, Investment, and Growth. Tokyo Club Papers, Vol.12, p.55-74, 1999.

CARKOVIC, M.; LEVINE, R. Does Foreign Direct Investment Accelerate Economic Growth? In: MORAN, T. H.; GRAHAM, E. M.; BLOMSTROM, M. Does Foreign Direct Investment Promote Development? Washington: Institute for International Economics, 2005.

CASELli, F.; ESQUIVEL, G.; LEFORT, F. Reopening the Convergence Debate: A New Look at Cross-Country Growth Empirics. Journal of Economic Growth, Vol. 1, no 3, p.363-389, 1996.

CORDEN, W. M. The geometric representation of policies to attain internal and external balance. Review of Economic Studies, Vol.18, nº 1, p.1-22, 1960.

DELL'ARICCIA, G.; DI GIOVANNI, J.; FARIA, A.; KOSE, M. A.; MAURO, P.; SCHINDLER, M.; TERRONES, M. OSTRY, J. D. Reaping the Benefits of Financial Globalization. IMF Occasional Paper $\mathrm{n}^{\circ}$ 264, 2008.

DORNBUSH, R. Tariffs and nontraded goods. Journal of International Economics. Vol. 4, $\mathrm{n}^{\circ} 2$, p. 177-185, 1974.

DURHAM, J. B. Absorptive Capacity and the Effects of Foreign Direct Investment and Equity Foreign Portfolio Investment on Economic Growth. European Economic Review, Vol. 48, $\mathrm{n}^{\circ} 2, \mathrm{p} .285-306,2004$.

EDISON, H. J.; LEVINE, R.; RICCI, A. L.; SLØK, T. International Financial Integration and Economic Growth. Journal of International Money and Finance, Vol.21, nº 6, p.749-776, 2002.

EICHENGREEN, B. The Cautious Case for Capital Flows. University of California, Working Papers, 2007.

EICHENGREEN, B. Taming Capital Flows. World Development, Vol.28, nº 6, p.1105-1116, 2000.

EICHENGREEN, B.; MUSSA, M.; DELL'ARICCIA, G.; DETRAGIACHE, E.; MILESI-FERRETTI, G. M.; TWEEDIE, A. Capital Account Liberalization: Theoretical and Practical Aspects. IMF Occasional Paper no 172, 1998.

HENRY, P. B. Capital Account Liberalization: Theory, Evidence, and Speculation. Journal of Economic Literature, Vol.45, $\mathrm{n}^{\circ}$ 4, p.887-935, 2007.

HERZER, D.; KLASEN, S.; NOWAK-KEHMANN, F. In Search of FDI-Led Growth in Developing Countries: The Way Forward. Economic Modelling, Vol. 25, nº 5, p.793-810, 2008.

INTERNATIONAL MONETARY FUND. World Economic Outlook Database. IMF: Washington, 2011.

INTERNATIONAL MONETARY FUND. International Financial Statistics. IMF: Washington, 2011.

Estud. Econ., São Paulo, vol. 43, n.4, p.773-811, out.-dez. 2013 
ISLAM, N. Growth Empirics: A Panel Data Approach. Quarterly Journal of Economics, Vol. 110, $\mathrm{n}^{\circ}$. 4, p. 1127-1 170, November, 1995.

KOSE, M. A.; PRASAD, E.; ROGOFF, K.; WEI, S. Financial Globalization and Economic Policies. In: RODRIK, D.; ROSENZWEING, M (eds.). Handbook of Development Economics. The Netherlands: Elsevier BV., Vol. 5, 2010.

KORINEK, A. Capital Flows, Crises and Externalities. In: ALLEN, F.; AOKI, M.; KIYOTAKI, N.; GORDON, R.; STIGLITZ, J. E.; FITOUSSI, J. P. The Global Macro Economy and Finance. London: Palgrave Macmillan, 2012.

KORINEK, A. The New Economics of Prudential Capital Controls: A Research Agenda. IMF Economic Review, Vol. 59, $\mathrm{n}^{\circ}$ 3, p.523-561, 2011.

KOSE, M. A.; PRASAD, E.; ROGOFF, K.; WEI, S. Financial Globalization: A Reappraisal. IMF Staff Papers, Vol. 56, n 1, p.8-62, 2009.

LIPSEY, R. G. Reflections on the General Theory of Second Best at its Golden Jubilee. International Tax and Public Finance, Vol.14, nº 4, p.349-364, 2007.

OBSTFELD, M. International Finance and Growth in Developing Countries: What Have We Learned? IMF Staff Papers, Vol. 56, nº 1, p.63-111, 2009.

OBSTFELD, M.; ROGOFF, K. Foundations of International Macroeconomics. Cambridge, Massachusetts: The MIT Press, 1996.

OSTRY, J. D.; GHOSH, A. R.; HABERMEIER, K.; LAEVEN, L.; CHAMON, M.; QURESHI, M. S.; KOKENYNE, A. Managing Capital Inflows: What Tools to Use? IMF Staff Discussion Note ${ }^{\circ}$ 6, 2011.

POLITICAL SERVICE RISK GROUP. International Country Risk Guide. PSRG: Nova York, 2011.

PRASAD, E., RAJAN, R., SUBRAMANIAN, A. Foreign Capital and Economic Growth. Brookings Papers on Economic Activity, Vol. 38, n 1, p. 153-230, 2007.

REISEN, H.; SOTO, M. Which Types of Capital Inflows Foster Developing-Country Growth? International Finance, Vol.4, no 1, p.1-14, 2001.

RODRIK, D.; SUBRAMANIAN, A. Why Did Financial Globalization Disappoint? IMF Staff Papers, Vol. 56, n 1, p.112-138, 2009.

RODRIK, D. Who Needs Capital-Account Convertibility? In: PETER, B. K. (ed). Should the IMF Pursue Capital-Account Convertibility? Princeton University, Department of Economics, Essays in International Finance n ${ }^{\circ} 207,1998$.

ROODMAN, D. How to Do xtabond2: An Introduction to Difference and System GMM in Stata. The Stata Journal, Vol. 9, nº 1, p.86-136, 2009.

SALTER, W. E. Internal and external balance: The role of price and expenditure effects. Economic Record, Vol. 71, nº 35, p.226-238, 1959.

STIGLITZ, J. E. Contagion, Liberalization, and the Optimal Structure of Globalization. Journal of Globalization and Development, Vol.1, nº 2, p.1-45, 2010.

STIGLITZ, J. E. Capital-Market Liberalization, Globalization, and the IMF. Oxford Review of Economic Policy, Vol.20, nº 1, p.57-71, 2004.

STIGLITZ, J. Capital Market Liberalization, Economic Growth, and Instability. World Development, Vol. 28, nº 6, p. 1075-1086, 2000.

SWAN, T. W. Economic control in a dependent economy. Economic Record, Vol. 73, n 36, p.51-66, 1960.

WINDMEIJER, F. A Finite Sample Correction for the Variance of Linear Efficient Two-Step GMM Estimators. Journal of Econometrics, Vol. 126, n 1, p.25-51, 2005.

WOOLDRIDGE, J. M. Econometric Analysis of Cross Section and Panel Data. 2. ed. Cambridge, MA: The MIT Press, 2010.

WORLD BANK. World Development Indicators. WB: Washington, 2011.

Estud. Econ., São Paulo, vol. 43, n.4, p.773-811, out.-dez. 2013 


\section{Apêndice}

\section{Tabela Al - Descrição e fonte de variáveis}

\begin{tabular}{|c|c|c|}
\hline Variáveis & Descrição & Fonte \\
\hline $\begin{array}{l}\text { Crescimento do } \\
\text { PIB per capita }\end{array}$ & $\begin{array}{l}\text { Taxa de crescimento do PIB per capita real (\%), incluída na equação de cresci- } \\
\text { mento como a média anual para cada período de cinco anos. O PIB per capita é } \\
\text { PPP, está em \$ internacional, constante de } 2005 \text {. }\end{array}$ & $\begin{array}{l}\text { World Development } \\
\text { Indicators (2011) }\end{array}$ \\
\hline PIB Inicial & $\begin{array}{l}\text { Nível do PIB per capita real, incluída na equação de crescimento como o logaritmo } \\
\text { natural no ano inicial de cada período de cinco anos. O PIB per capita é PPP, está } \\
\text { em \$ internacional, constante de } 2005 .\end{array}$ & $\begin{array}{l}\text { World Development } \\
\text { Indicators (2011) }\end{array}$ \\
\hline Capital Humano & $\begin{array}{l}\text { Média dos anos de escolaridade da população com idade superior a } 25 \text { anos, in- } \\
\text { cluída na equação de crescimento como o nível no ano inicial de cada período de } \\
\text { cinco anos. }\end{array}$ & Barro e Lee (2010) \\
\hline Investimento & $\begin{array}{l}\text { Formação bruta de capital fixo como \% do PIB, incluída na equação de crescimen- } \\
\text { to como a média anual para cada período de cinco anos. }\end{array}$ & $\begin{array}{l}\text { World Development } \\
\text { Indicators (2011) }\end{array}$ \\
\hline População & $\begin{array}{l}\text { Taxa de crescimento da população (\%), incluída na equação de crescimento como } \\
\text { a média anual para cada período de cinco anos. }\end{array}$ & $\begin{array}{l}\text { World Development } \\
\text { Indicators (2011) }\end{array}$ \\
\hline Conta Corrente & $\begin{array}{l}\text { Saldo em conta corrente do balanço de pagamentos, expresso como \% do PIB, } \\
\text { multiplicado por }-1 \text {, incluída na equação de crescimento como média anual para } \\
\text { cada período de cinco anos. Um valor positivo significa déficit em conta corrente, } \\
\text { importação de capital/poupança externa. }\end{array}$ & $\begin{array}{l}\text { World Economic } \\
\text { Outlook Database } \\
\text { (2011) }\end{array}$ \\
\hline $\begin{array}{l}\text { Fluxo Total } \\
\text { de Capitais }\end{array}$ & $\begin{array}{l}\text { Soma da entrada líquida de Investimento Externo Direto, Investimento de Portfólio } \\
\text { e Outros Investimentos, como \% do PIB, incluída na equação de crescimento como } \\
\text { média anual para cada período de cinco anos. }\end{array}$ & $\begin{array}{l}\text { International Financial } \\
\text { Statistic (2011) }\end{array}$ \\
\hline $\begin{array}{l}\text { Investimento } \\
\text { Externo Direto }\end{array}$ & $\begin{array}{l}\text { Entrada líquida de Investimento Externo Direto, como \% do PIB, incluída na equa- } \\
\text { ção de crescimento como média anual para cada período de cinco anos. }\end{array}$ & $\begin{array}{l}\text { International Financial } \\
\text { Statistic (2011) }\end{array}$ \\
\hline $\begin{array}{l}\text { Investimento } \\
\text { de Portfólio }\end{array}$ & $\begin{array}{l}\text { Entrada líquida de Investimento de Portfólio, como \% do PIB, incluída na equação } \\
\text { de crescimento como a média anual para cada período de cinco anos. }\end{array}$ & $\begin{array}{l}\text { International Financial } \\
\text { Statistic (2011) }\end{array}$ \\
\hline $\begin{array}{l}\text { Outros } \\
\text { Investimentos }\end{array}$ & $\begin{array}{l}\text { Entrada líquida de Outros Investimentos, como \% do PIB, incluída na equação de } \\
\text { crescimento como a média anual para cada período de cinco anos. }\end{array}$ & $\begin{array}{l}\text { International Financial } \\
\text { Statistic (2011) }\end{array}$ \\
\hline Fluxo Equity & $\begin{array}{l}\text { Soma da entrada líquida de Investimento Externo Direto e Investimento de Portfólio } \\
\text { Equity, como \% do PIB, incluída na equação de crescimento como média anual } \\
\text { para cada período de cinco anos. }\end{array}$ & $\begin{array}{l}\text { International Financial } \\
\text { Statistic (2011) }\end{array}$ \\
\hline Fluxo Debt & $\begin{array}{l}\text { Soma da entrada líquida de Outros Investimentos e Investimento de Portfólio Debt, } \\
\text { como \% do PIB, incluída na equação de crescimento como média anual para cada } \\
\text { período de cinco anos. }\end{array}$ & $\begin{array}{l}\text { International Financial } \\
\text { Statistic (2011) }\end{array}$ \\
\hline Lei \& Ordem & $\begin{array}{l}\text { É um índice que controla para a qualidade do ambiente institucional, cuja definição } \\
\text { é:"Two measures comprising one risk component. Each sub-component equals } \\
\text { half of the total. The "law" sub-component assesses the strength and impartiality of } \\
\text { the legal system, and the "order" sub-component assesses popular observance of } \\
\text { the law" (ICRG, 2011). Escala de } 0 \text { a } 6 \text {, com um alto valor significando baixo risco. }\end{array}$ & $\begin{array}{l}\text { International Country } \\
\text { Risk Guide (2011) }\end{array}$ \\
\hline Comércio & $\begin{array}{l}\text { Soma de importações + exportações de bens e serviços como \% do PIB, incluída } \\
\text { na equação de crescimento como a média anual para cada período de cinco anos. }\end{array}$ & $\begin{array}{l}\text { World Development } \\
\text { Indicators (2011) }\end{array}$ \\
\hline Crédito & $\begin{array}{l}\text { Crédito ao setor privado como \% do PIB, incluída na equação de crescimento como } \\
\text { a média anual para cada período de cinco anos. }\end{array}$ & $\begin{array}{l}\text { World Development } \\
\text { Indicators (2011) }\end{array}$ \\
\hline Governo & $\begin{array}{l}\text { Gastos do governo em consumo como \% do PIB, incluída na equação de cresci- } \\
\text { mento como a média anual para cada período de cinco anos. }\end{array}$ & $\begin{array}{l}\text { World Development } \\
\text { Indicators (2011) }\end{array}$ \\
\hline Inflação & $\begin{array}{l}\text { Variação anual \% do índice de preço ao consumidor, incluída na equação de cres- } \\
\text { cimento como a média anual para cada período de cinco anos. }\end{array}$ & $\begin{array}{l}\text { World Development } \\
\text { Indicators (2011) }\end{array}$ \\
\hline
\end{tabular}




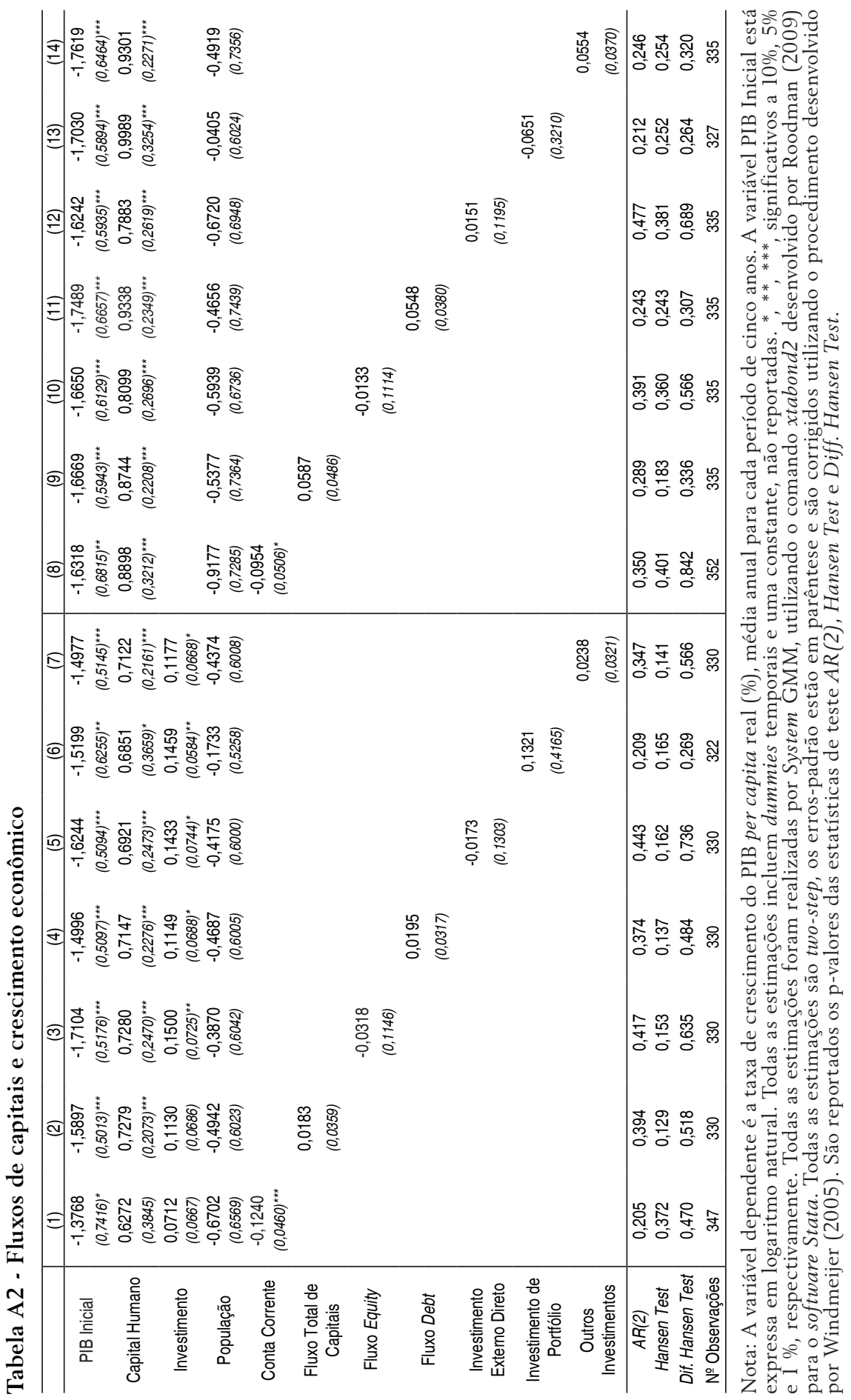




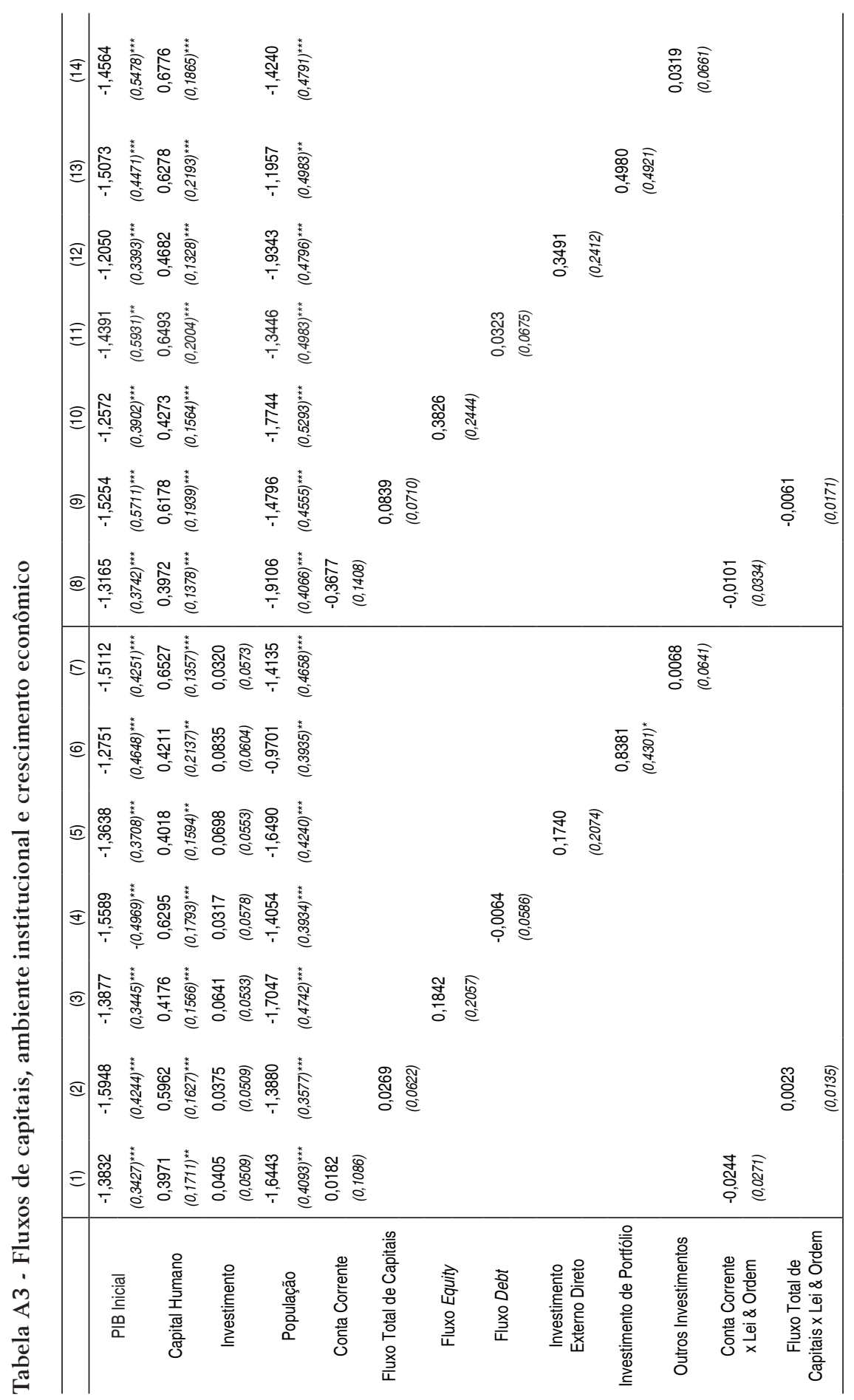




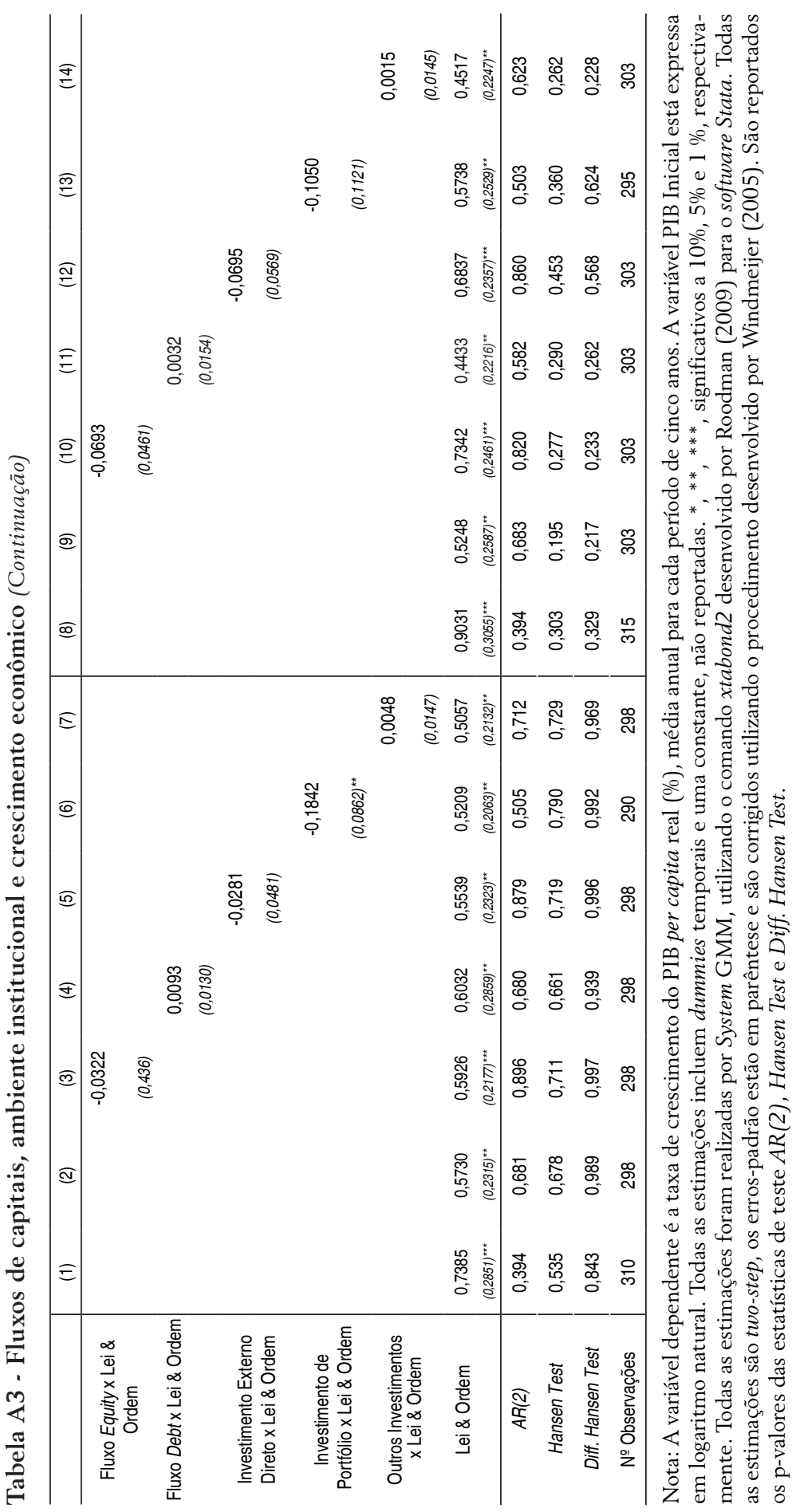




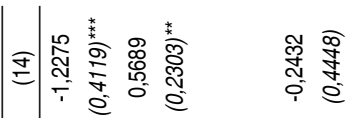

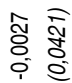

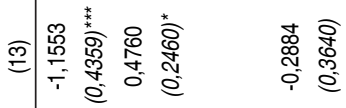

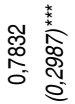

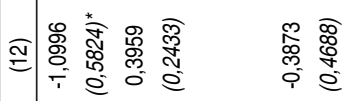

$\frac{\sqrt{2}}{\frac{N}{0}} \frac{\sqrt{2}}{0}$

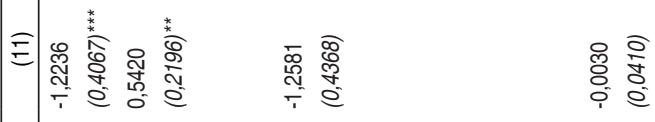

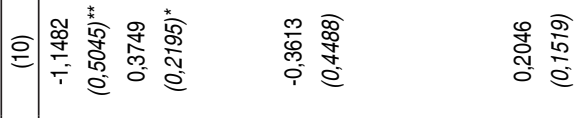

.

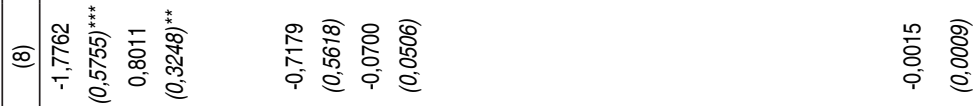

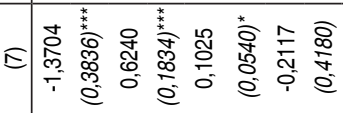

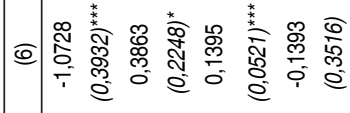

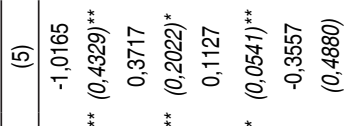

造

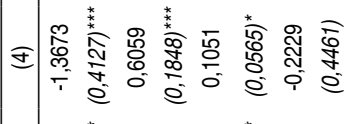

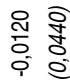

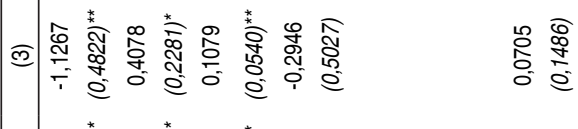

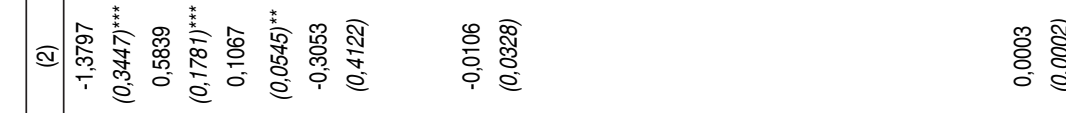

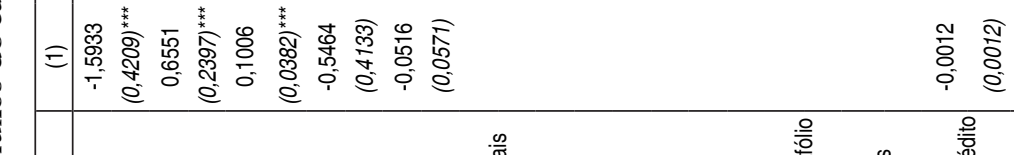

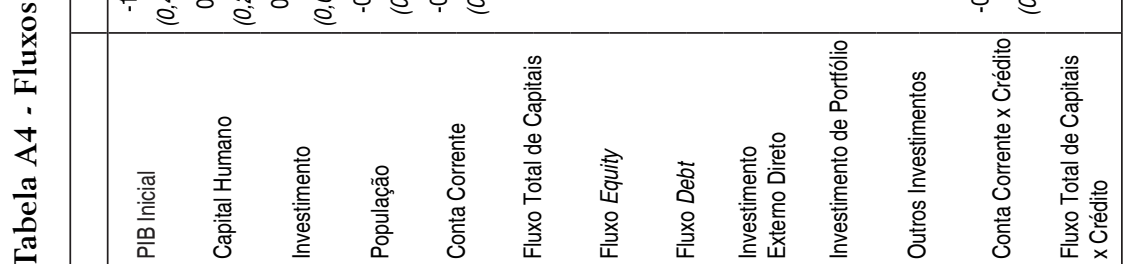




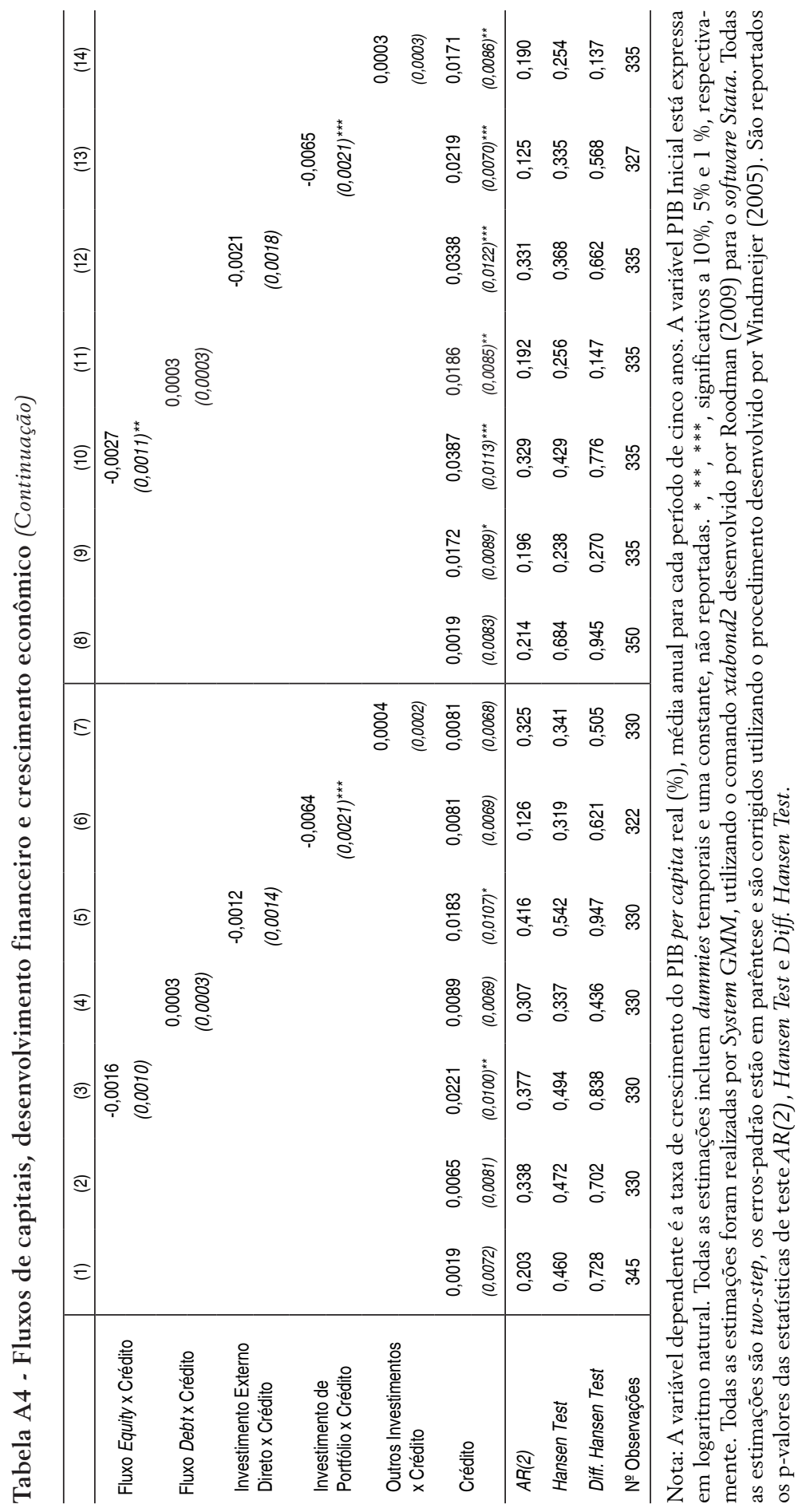




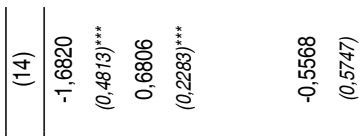

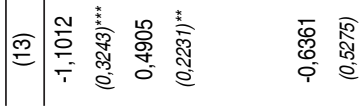

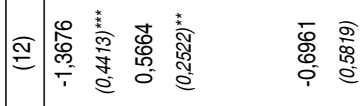

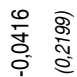

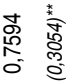

$\frac{\sqrt{2}}{4}$

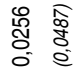

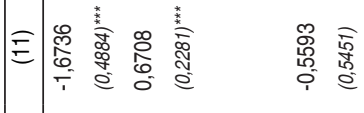

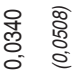

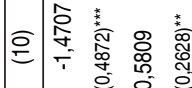

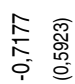

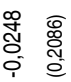

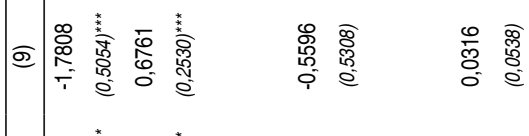

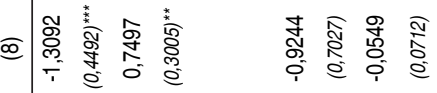

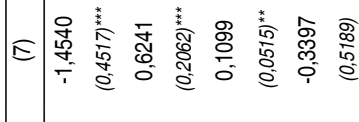

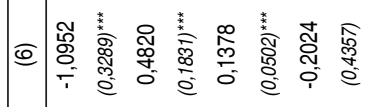

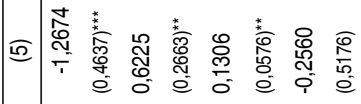

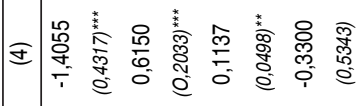

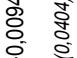

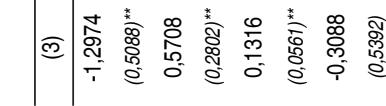

㠃

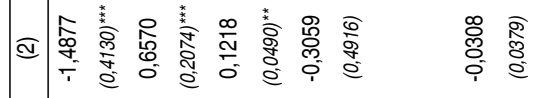




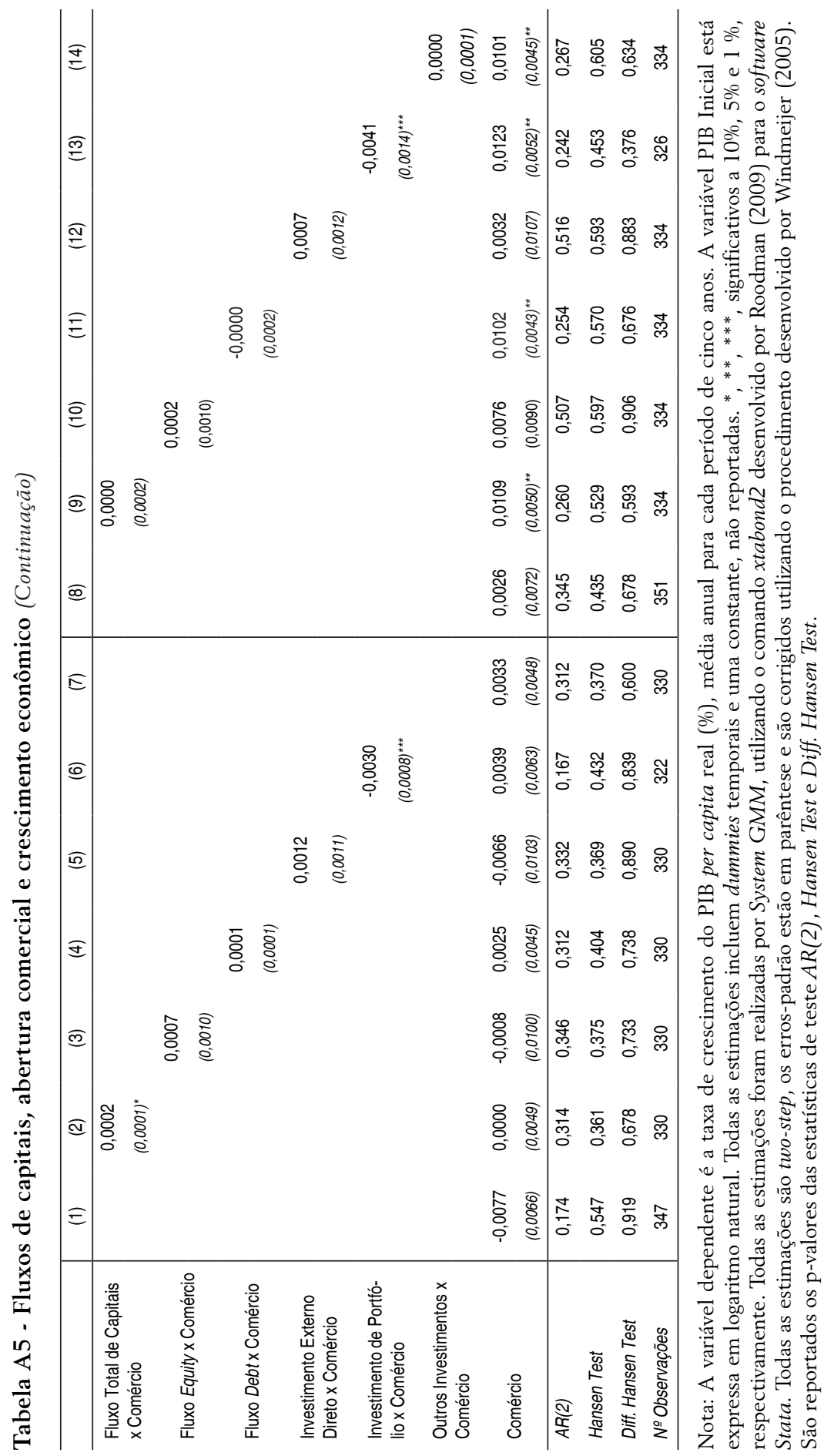




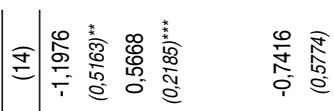

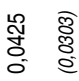

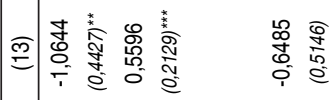

$\begin{array}{ll}\bar{m} & \mathbb{6} \\ 0 & 0 \\ 0 & 0 \\ 0 & 0\end{array}$

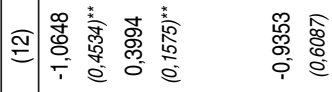

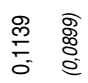

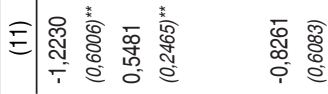

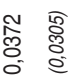

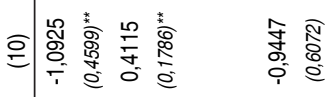

\begin{tabular}{ll}
$\overline{5}$ & \multicolumn{1}{c}{} \\
0 & 0 \\
0 & 0 \\
0 & 0
\end{tabular}

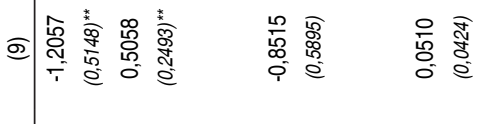

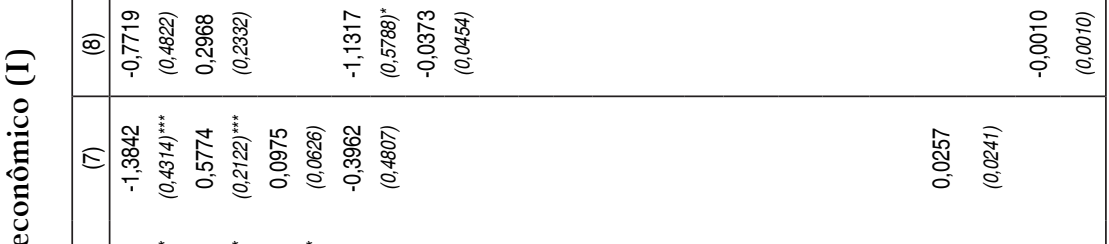

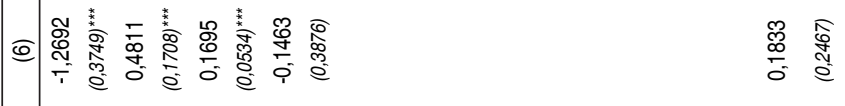

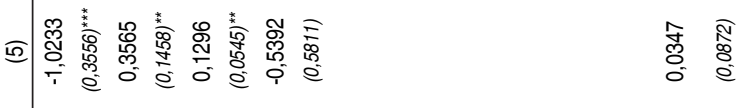

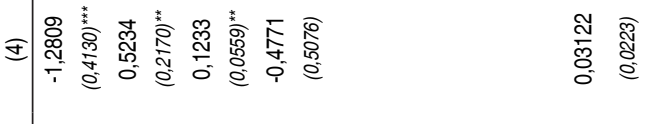

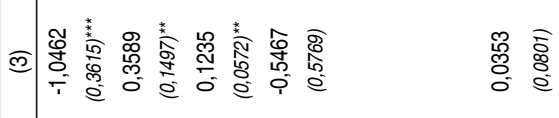

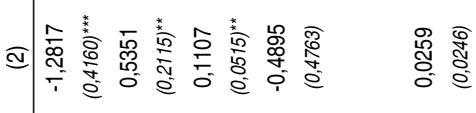

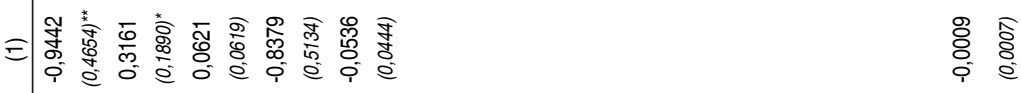

$\frac{\stackrel{0}{0}}{\frac{\pi}{2}}$

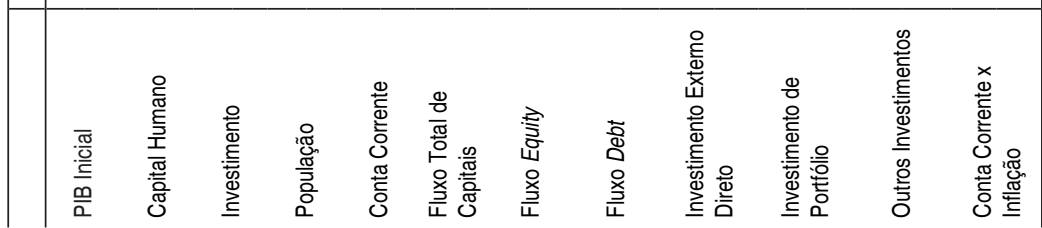




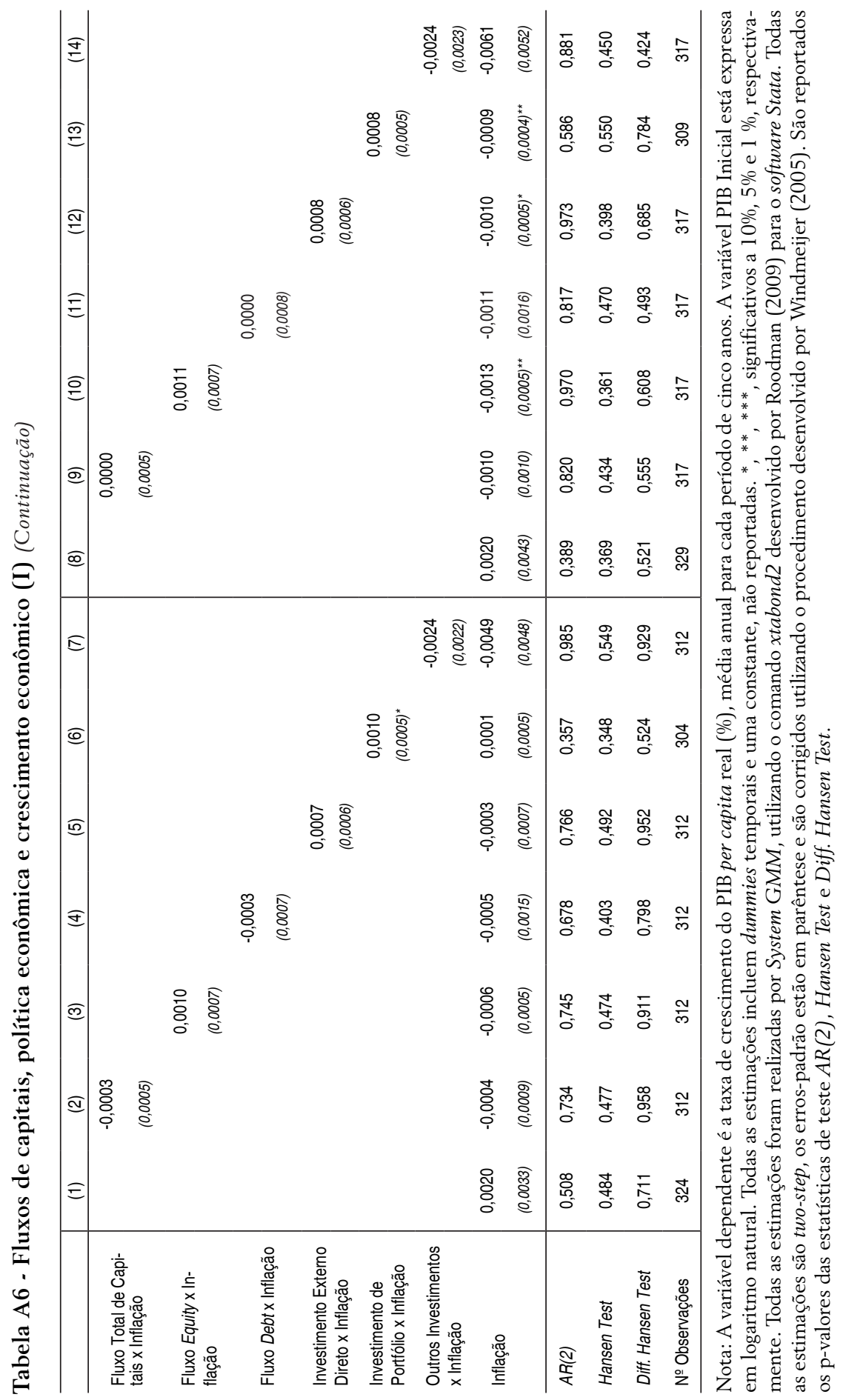




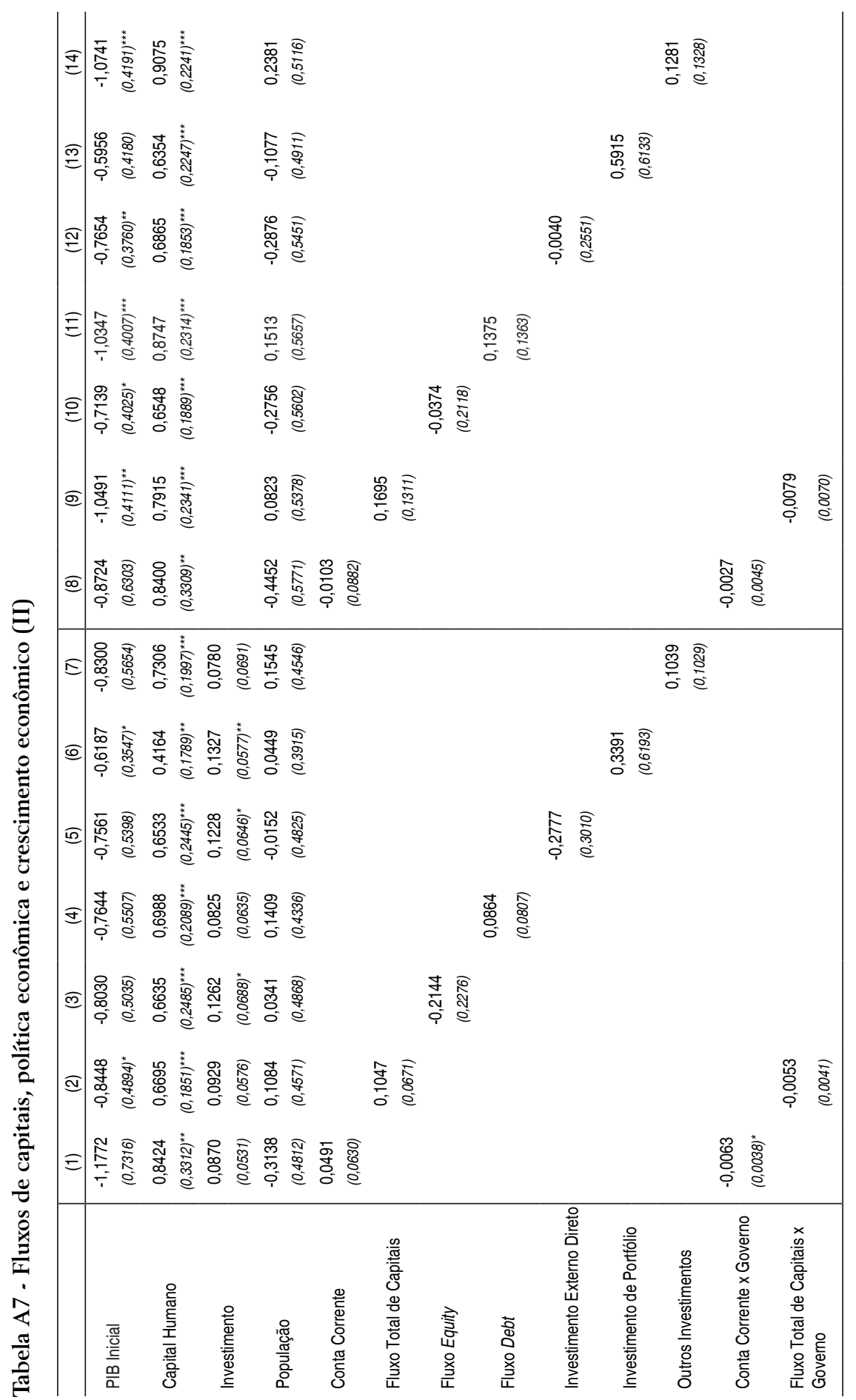




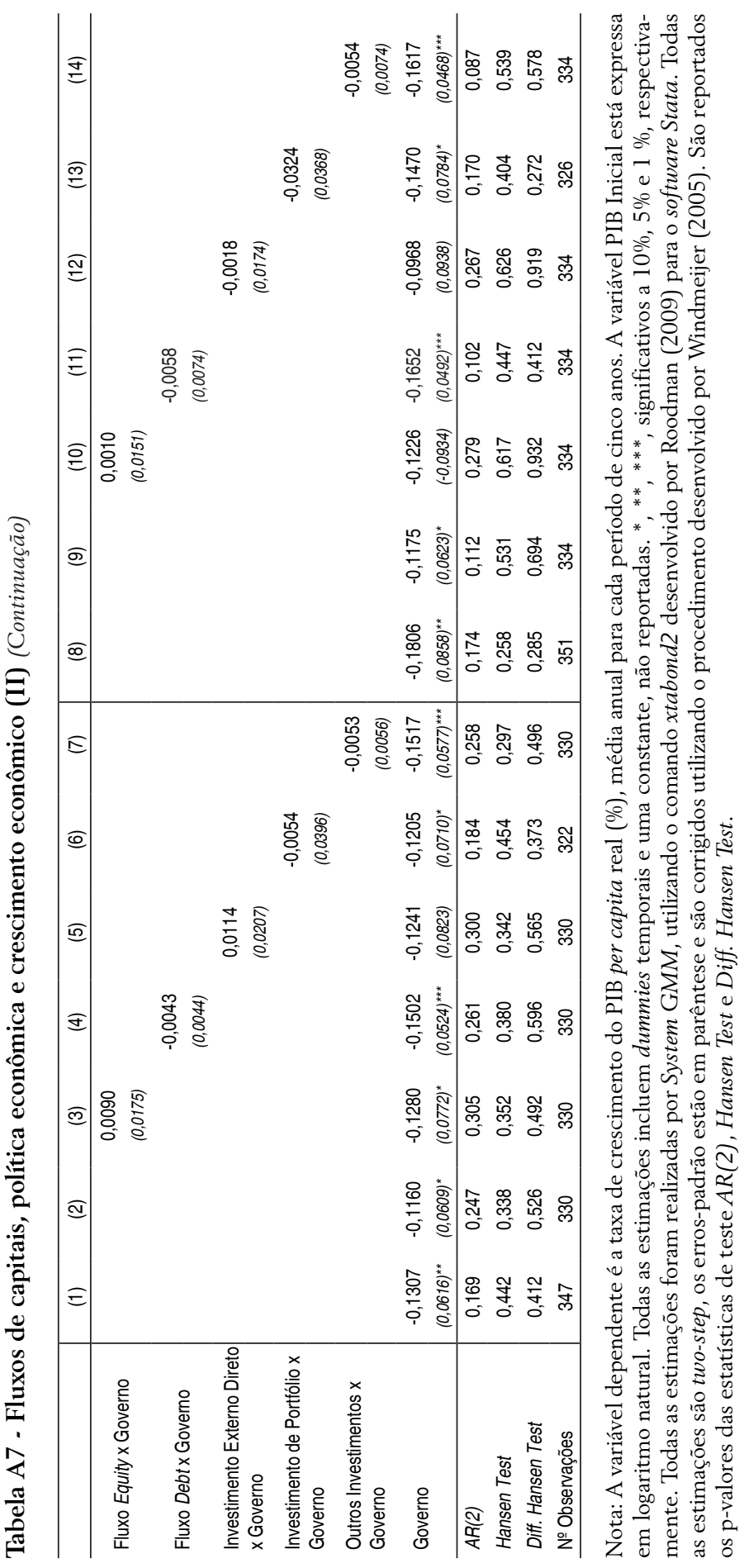


Tabela A8 - Fluxos de capitais, capital humano e crescimento econômico

\begin{tabular}{|c|c|c|c|c|}
\hline & (1) & (2) & (3) & (4) \\
\hline \multirow[t]{2}{*}{ PIB Inicial } & $-1,0262$ & $-0,9835$ & $-0,9184$ & $-1,0234$ \\
\hline & $(0,4240)^{\star \star}$ & $(0,4176)^{\star \star}$ & $(0,4316)^{\star \star}$ & $(0,4936)^{\star \star}$ \\
\hline \multirow[t]{2}{*}{ Capital Humano } & 0,4390 & 0,4662 & 0,4233 & 0,5684 \\
\hline & $(0,2286)^{*}$ & $(0,2637)^{*}$ & $(0,2130)^{\star *}$ & $(0,3211)^{*}$ \\
\hline \multirow[t]{2}{*}{ Investimento } & 0,1328 & 0,1252 & & \\
\hline & $(0,0554)^{\star \star}$ & $(0,0532)^{* *}$ & & \\
\hline \multirow[t]{2}{*}{ População } & $-0,5123$ & $-0,5710$ & $-0,6368$ & $-0,6066$ \\
\hline & $(0,6446)$ & $(0,6389)$ & $(0,5768)$ & $(0,5975)$ \\
\hline \multirow[t]{2}{*}{ Fluxo Equity } & 0,3525 & & 0,5270 & \\
\hline & $(0,2844)$ & & $(0,4335)$ & \\
\hline \multirow[t]{2}{*}{ Investimento Externo Direto } & & 0,3673 & & 0,5480 \\
\hline & & $(0,3125)$ & & $(0,5362)$ \\
\hline \multirow[t]{2}{*}{ Fluxo Equity x Capital Humano } & $-0,0398$ & & $-0,0537$ & \\
\hline & $(0,0371)$ & & $(0,0561)$ & \\
\hline \multirow[t]{2}{*}{ Investimento Externo Direto x Capital Humano } & & $-0,0466$ & & $-0,0656$ \\
\hline & & $(0,0454)$ & & $(0,0752)$ \\
\hline$A R(2)$ & 0,609 & 0,651 & 0,573 & 0,548 \\
\hline Hansen Test & 0,310 & 0,346 & 0,355 & 0,357 \\
\hline Diff. Hansen Test & 0,825 & 0,853 & 0,743 & 0,728 \\
\hline № Observações & 330 & 330 & 335 & 335 \\
\hline
\end{tabular}

Nota: A variável dependente é a taxa de crescimento do PIB per capita real (\%), média anual para cada período de cinco anos. A variável PIB Inicial está expressa em logaritmo natural. Todas as estimações incluem dummies temporais e uma constante, não reportadas. ${ }^{*},{ }^{* *},{ }^{* * *}$, significativos a $10 \%, 5 \%$ e $1 \%$, respectivamente. Todas as estimações foram realizadas por System GMM, utilizando o comando xtabond2 desenvolvido por Roodman (2009) para o software Stata. Todas as estimações são two-step, os erros-padrão estão em parêntese e são corrigidos utilizando o procedimento desenvolvido por Windmeijer (2005). São reportados os p-valores das estatísticas de teste AR(2), Hansen Test e Diff. Hansen Test. 


\begin{tabular}{|c|c|c|c|c|c|c|c|c|c|c|}
\hline & & 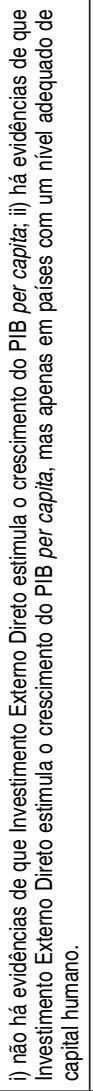 & 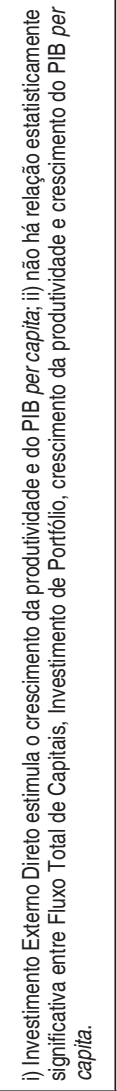 & 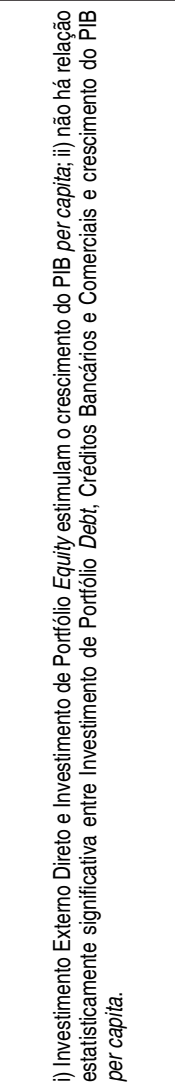 & 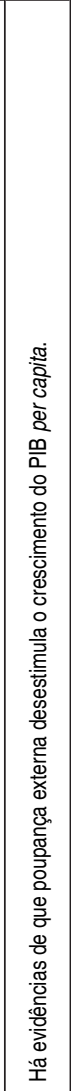 & 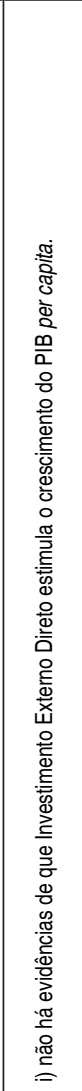 & 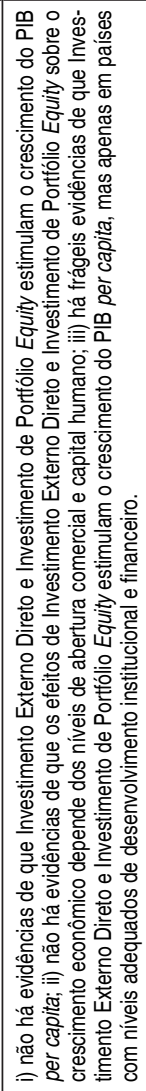 & 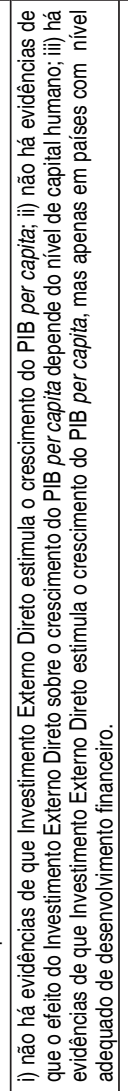 & 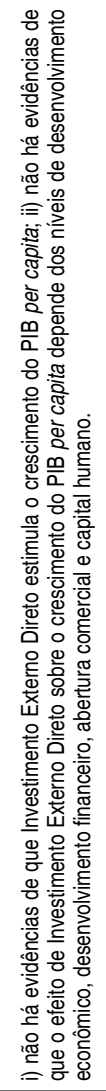 & 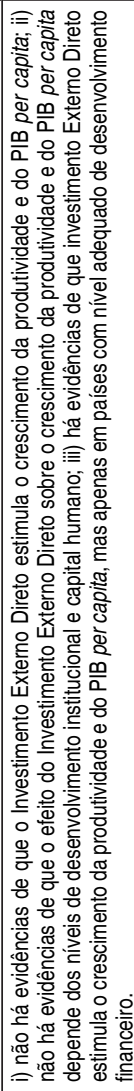 \\
\hline & דֶ, & 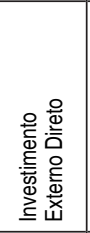 & 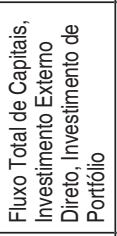 & 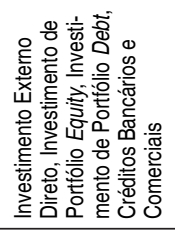 & 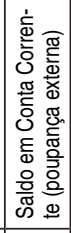 & 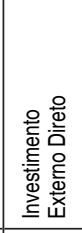 & 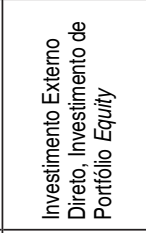 & 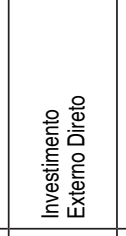 & 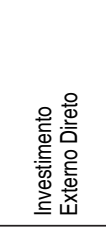 & 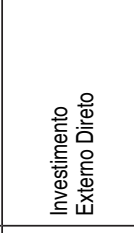 \\
\hline & ह & 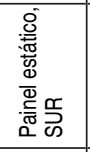 & 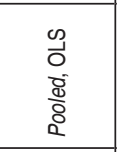 & 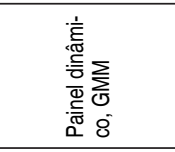 & 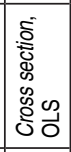 & 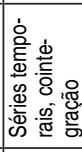 & 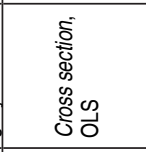 & 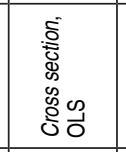 & 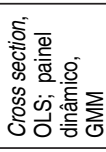 & 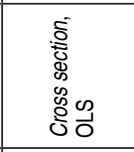 \\
\hline & $\frac{5}{5}$ & 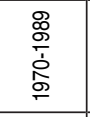 & 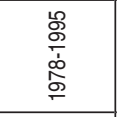 & 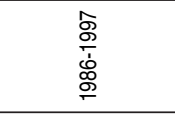 & $\begin{array}{l}\text { पे } \\
\text { ते } \\
\text { مे } \\
\text { के }\end{array}$ & $\begin{array}{l}\text { Oั. } \\
\text { مे } \\
\text { مे }\end{array}$ & ? & ஜூ & $\stackrel{8}{1}$ & 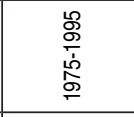 \\
\hline & , & 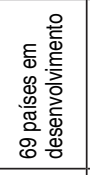 & 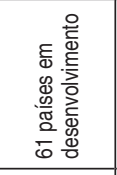 & 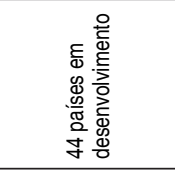 & 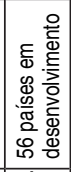 & 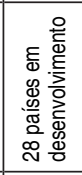 & 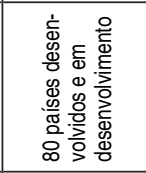 & 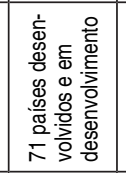 & 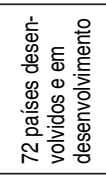 & 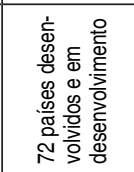 \\
\hline & & 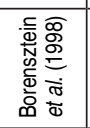 & 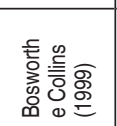 & 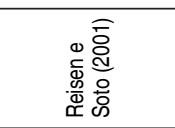 & 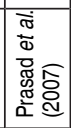 & 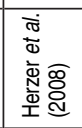 & 吝 & 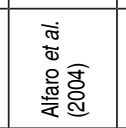 & 嘉 & 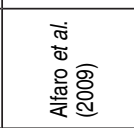 \\
\hline
\end{tabular}

